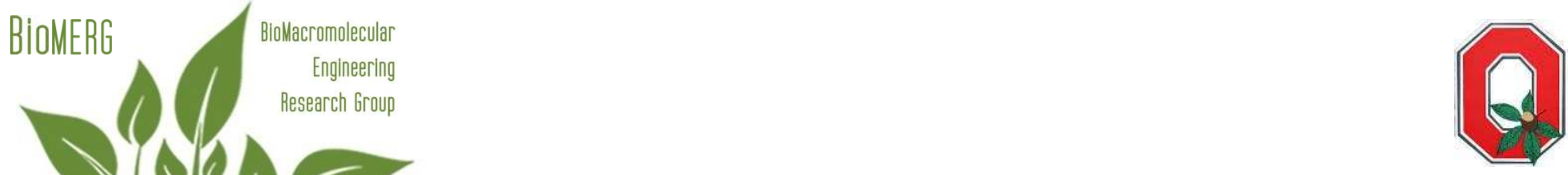

\title{
Synthesis and Characterization of Crosslinked Electrospun Fiber Mats from Allyl-functionalized Polysuccinimide
}

\author{
Judit E. Puskas, Kristof Molnar
}

College of Food, Agricultural, and Environmental Sciences

Ohio Agricultural Research and Development Center

Department of Food, Agricultural and Biological Engineering (FABE)

Wooster, OH USA

Benjamin Jozsa, Dora Barczikai, Angela Jedlovszki-Hajdu

Laboratory of Nanochemistry

Department of Biophysics and Radiation Biology

Semmelweis Medical University, HUNGARY

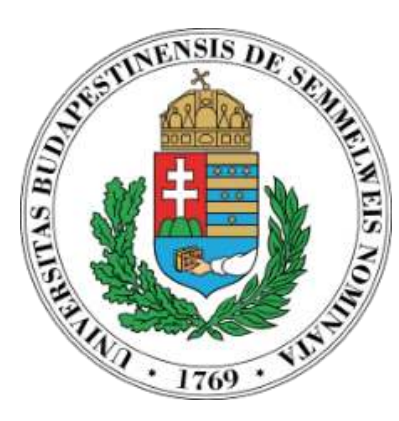




\section{World Production of Plastics}

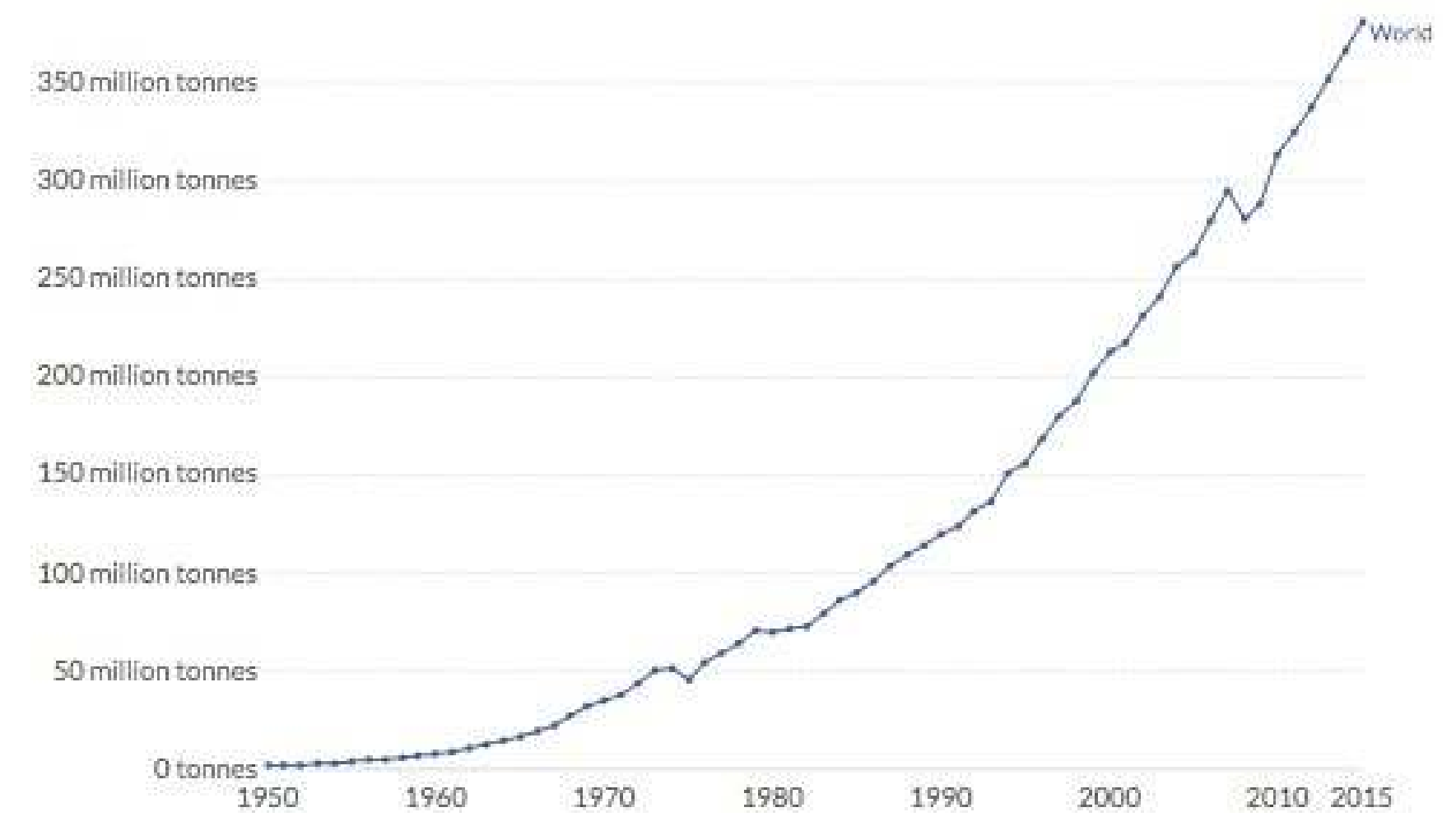

The world has produced (by 2015), 7.8 billion tons of plastic more than 1 ton for every person alive today! 


\section{Global Plastics Usage and Waste Generation}

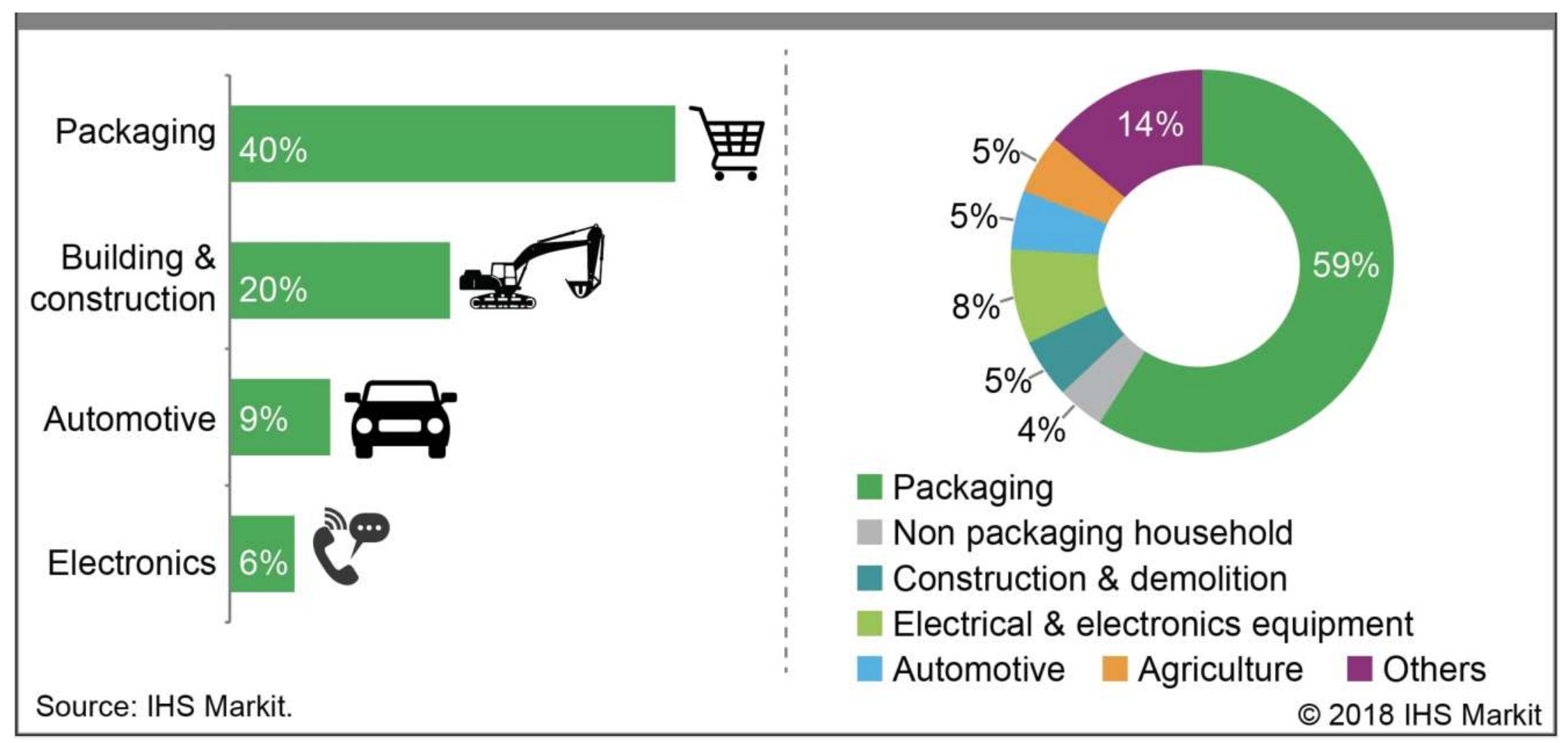

Courtesy of Prof. Miroslawa El Fray 


\section{Plastics Waste Generation}

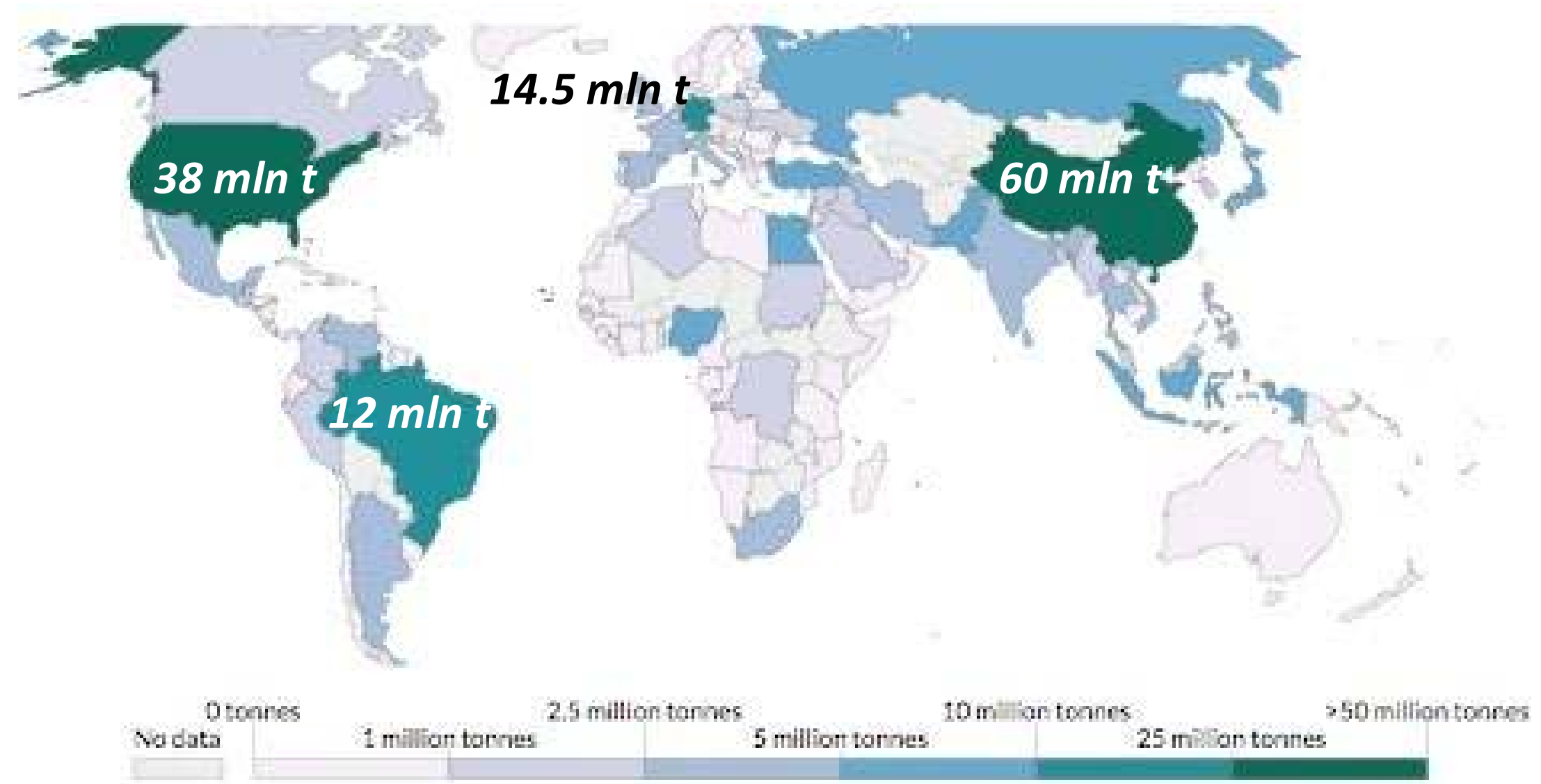




\section{Mismanaged Plastic Waste}

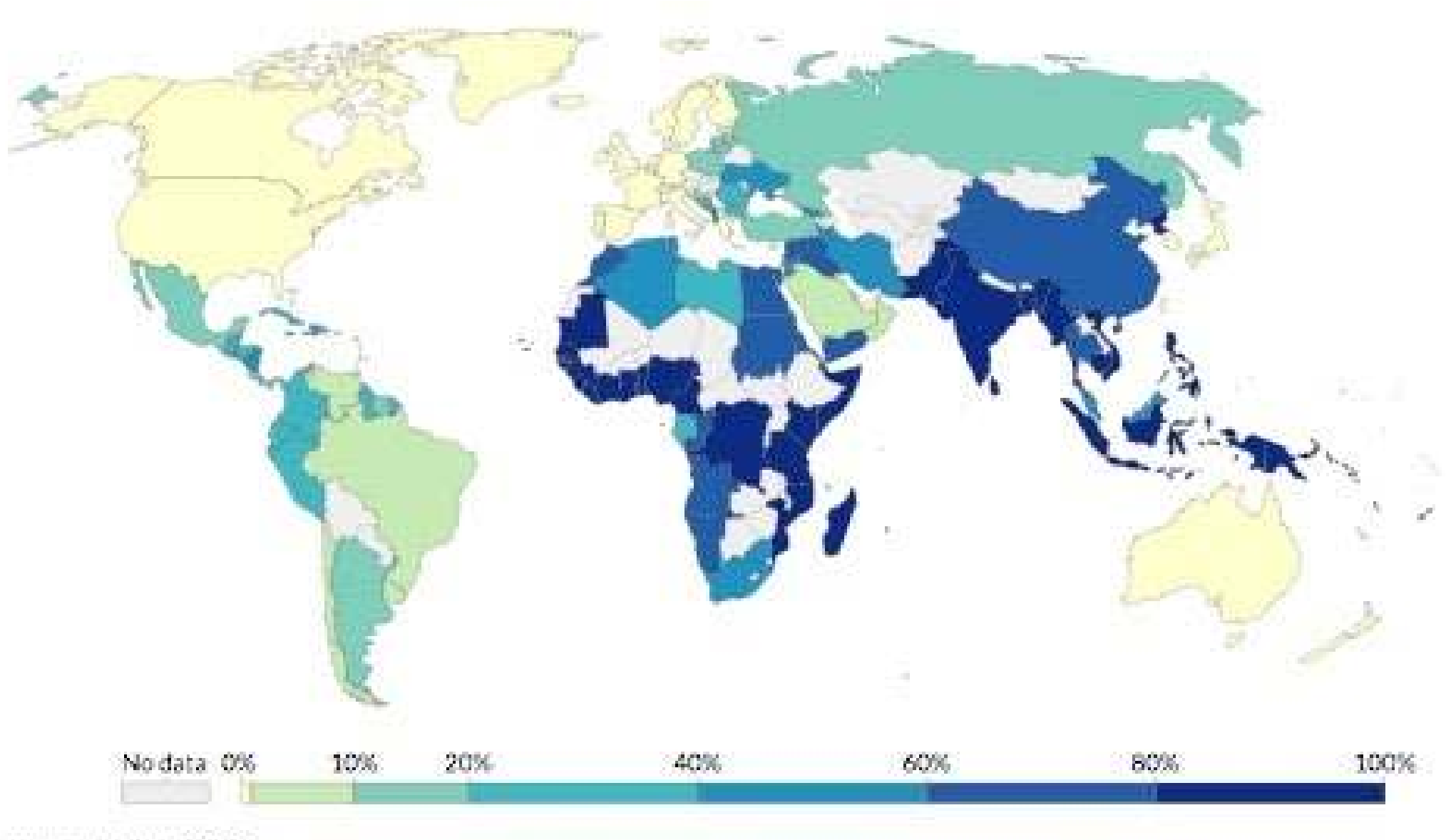




\section{“Green” Polymer Chemistry}

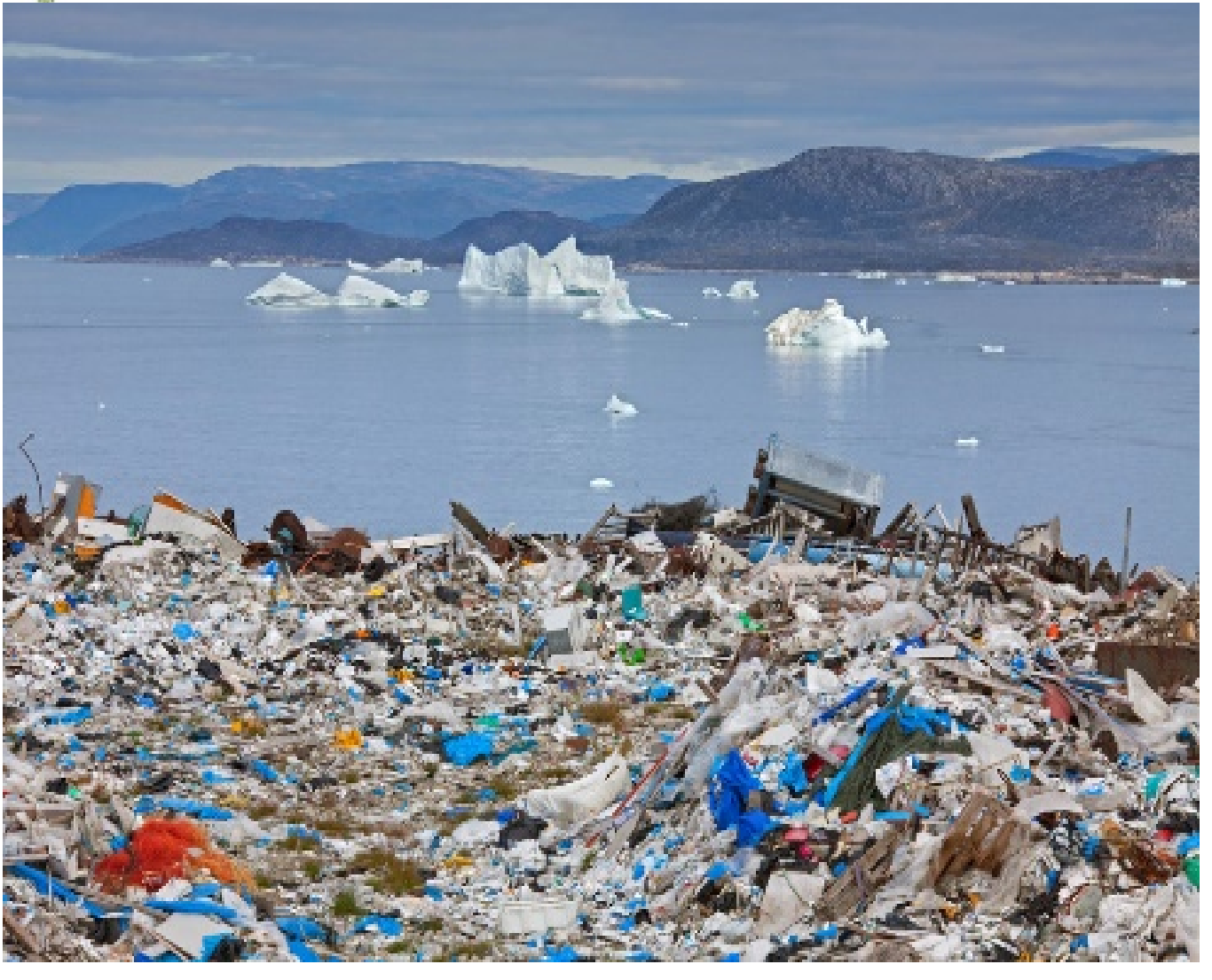

Plastic waste

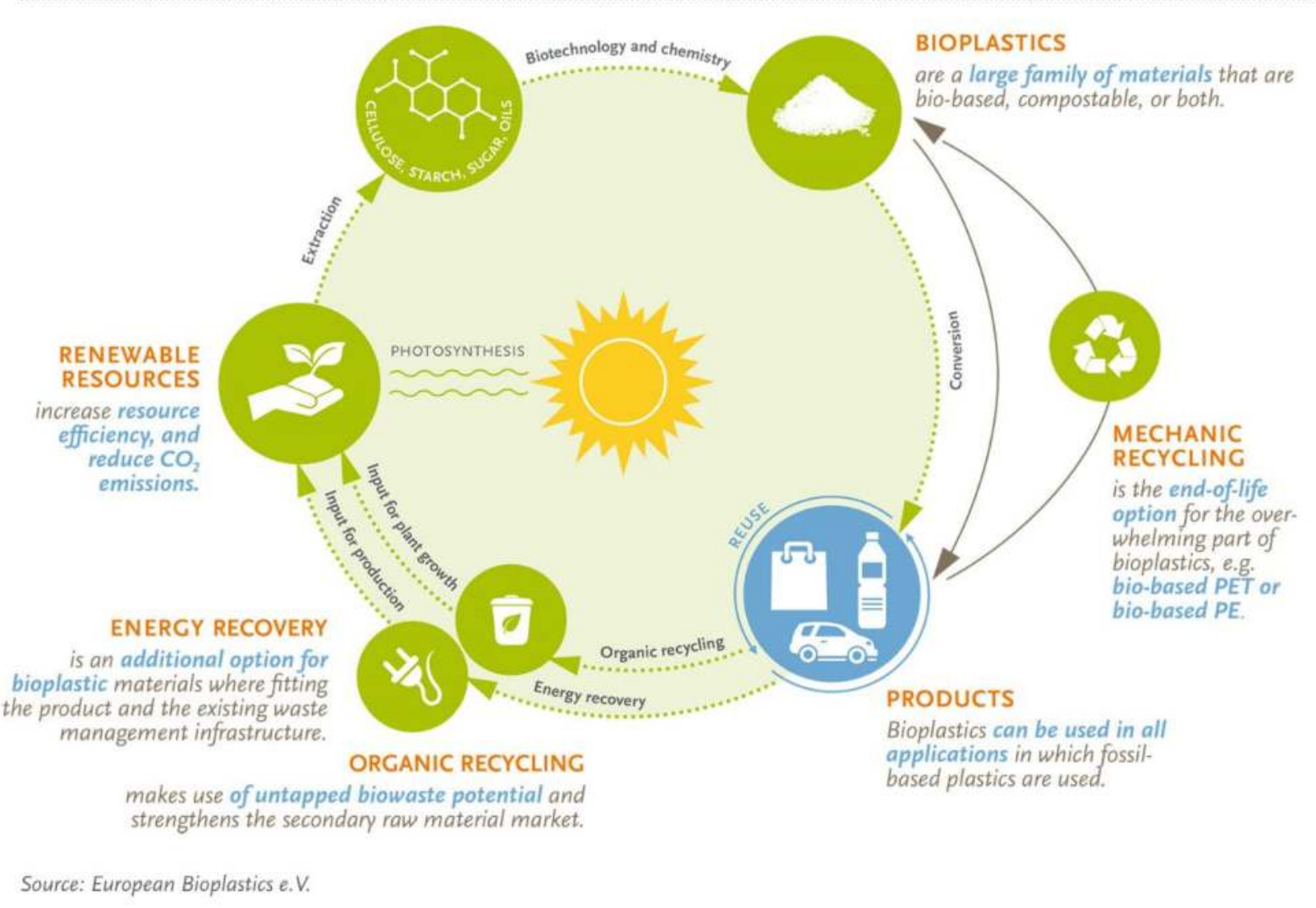

Bioplastics: Closing the Loop

Courtesy of Prof. Miroslawa El Fray 


\section{Polymers from Renewable Resources}

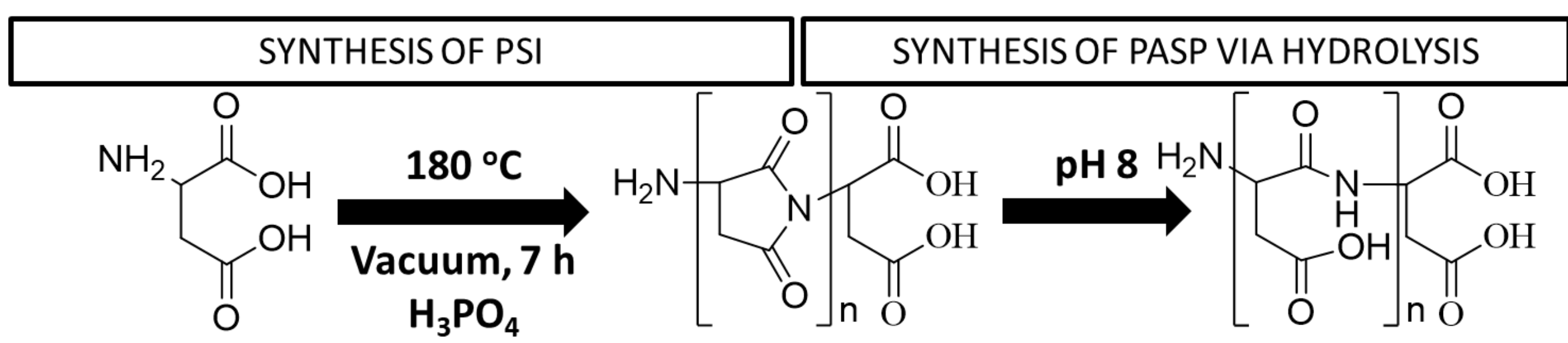

D,L- Aspartic acid

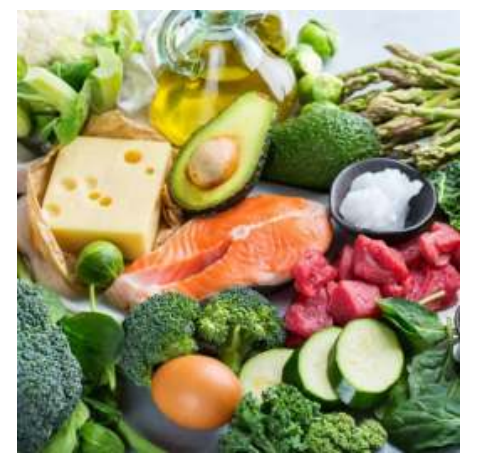

Polysuccinimide (PSI)

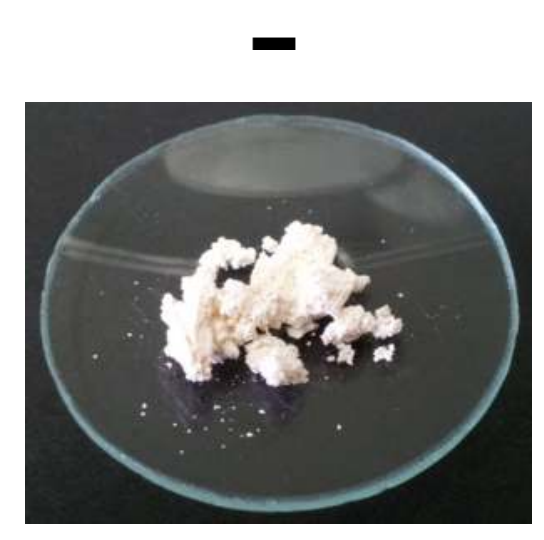

Poly(aspartic acid) (PASP)

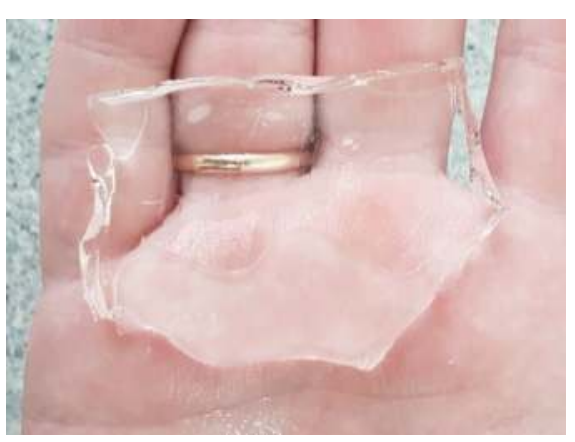

Crosslinked Swollen Hydrogel 


\section{Modification of PSI}

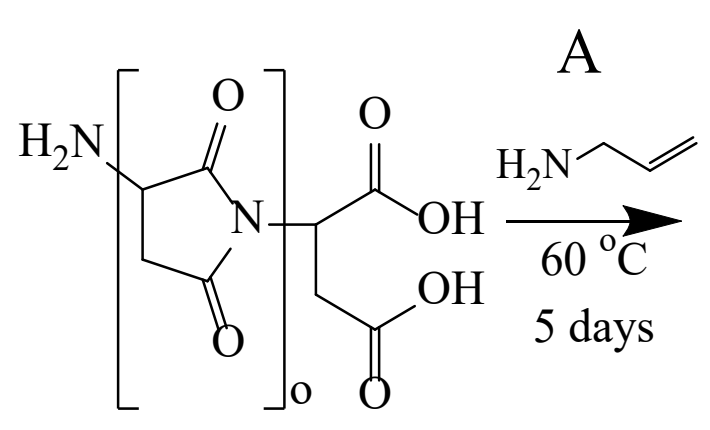

polysuccinimide (PSI)

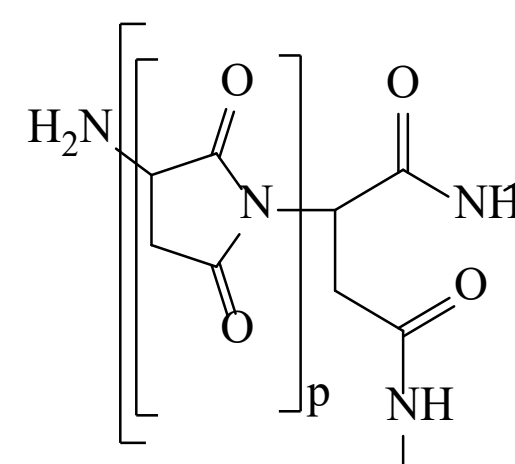

$\downarrow$

allylamine modified PSI (PSI-AA)
B

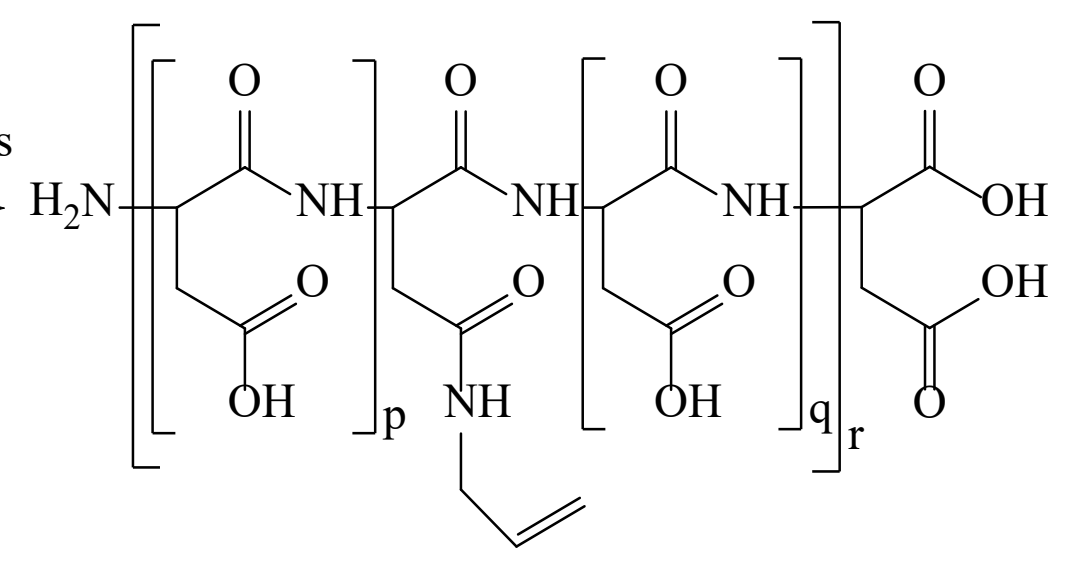

allylamine modified poly(aspartic acid) (PASP-AA)

Grafting Frequency: GF1, GF2, GF5, GF10 


\section{FTIR and NMR}
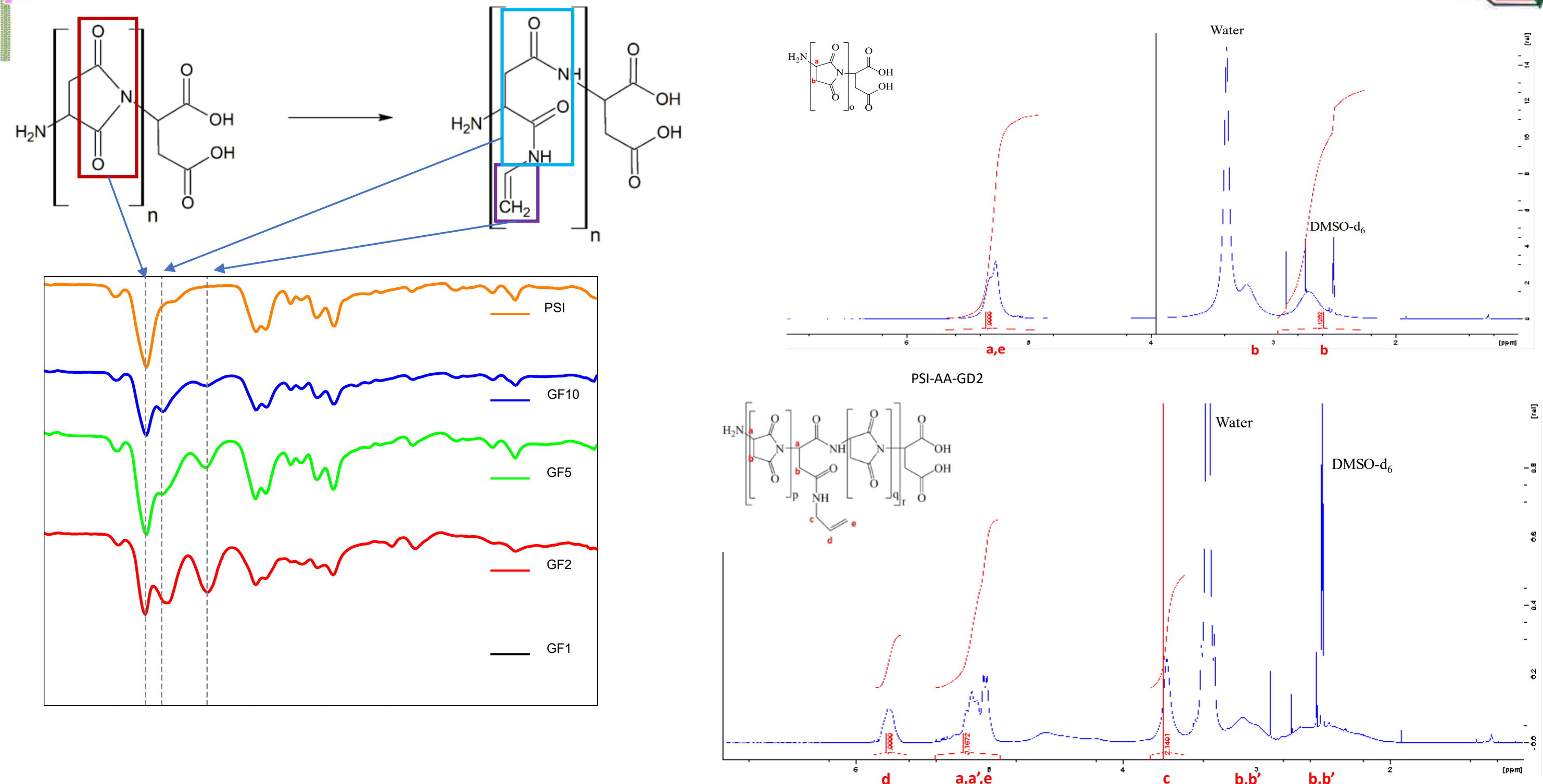


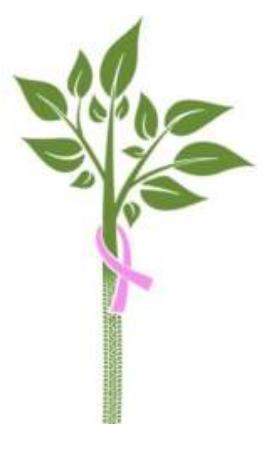

\section{Electrospinning}
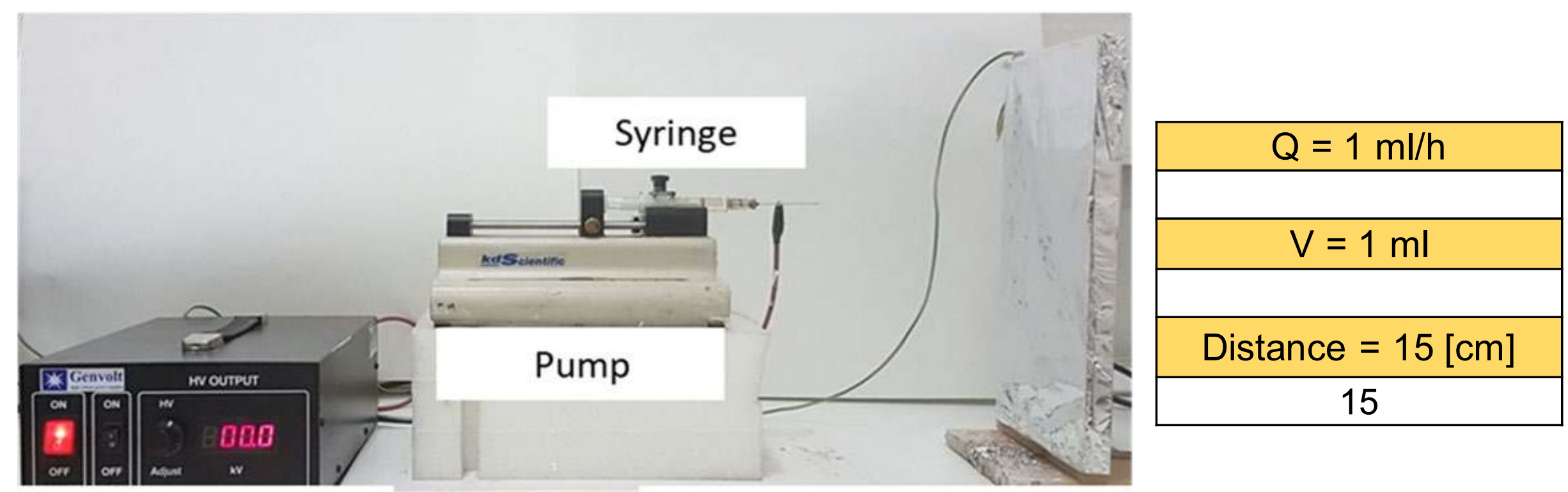

High voltage supply

Grounded metal collector

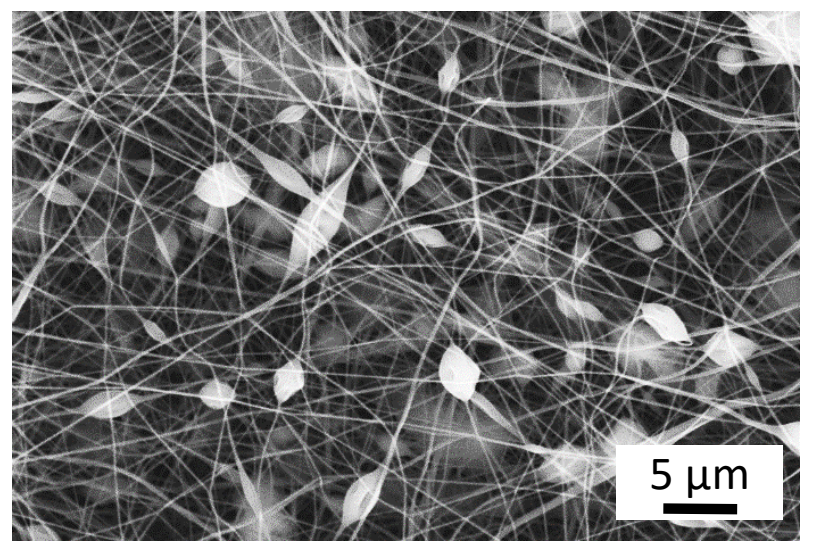

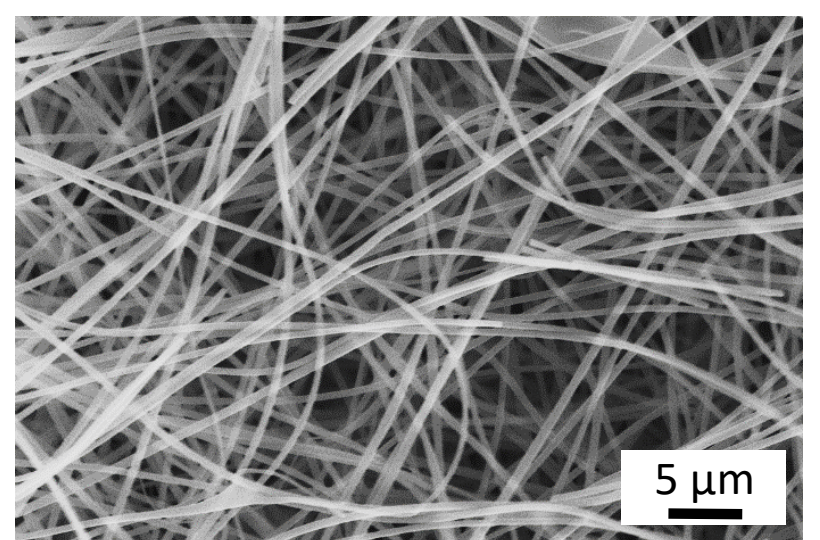

$35 \mathrm{wt} \%$

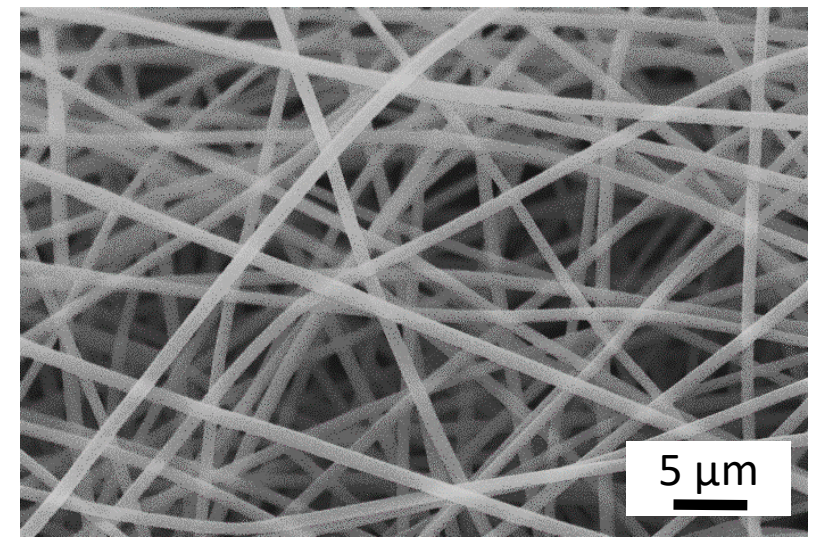

$45 w t \%$ 


\section{Plasma Treatment}

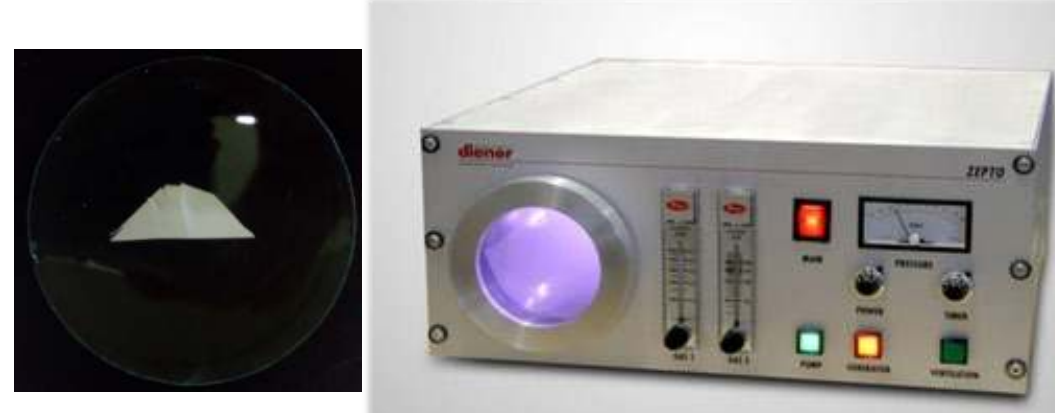

Low pressure air 13 minutes, $25 \mathrm{~W}$

Before

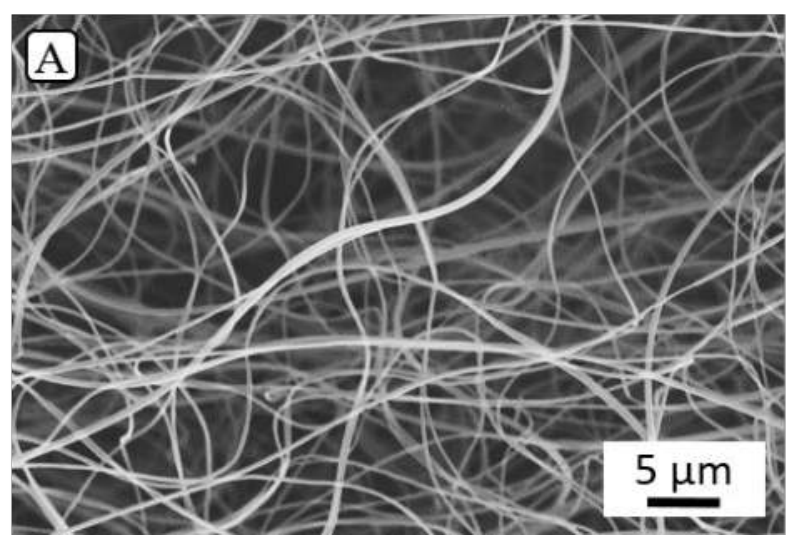

Soluble
After

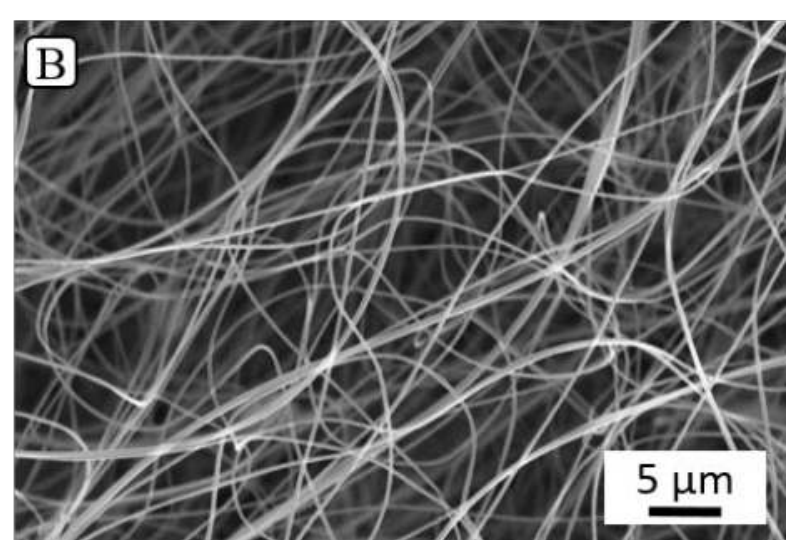

Insoluble

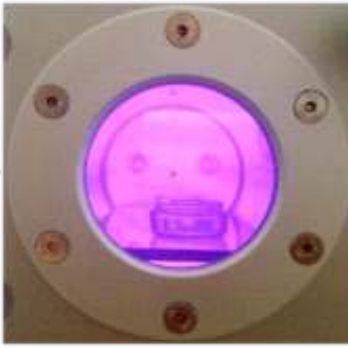




\section{XPS}
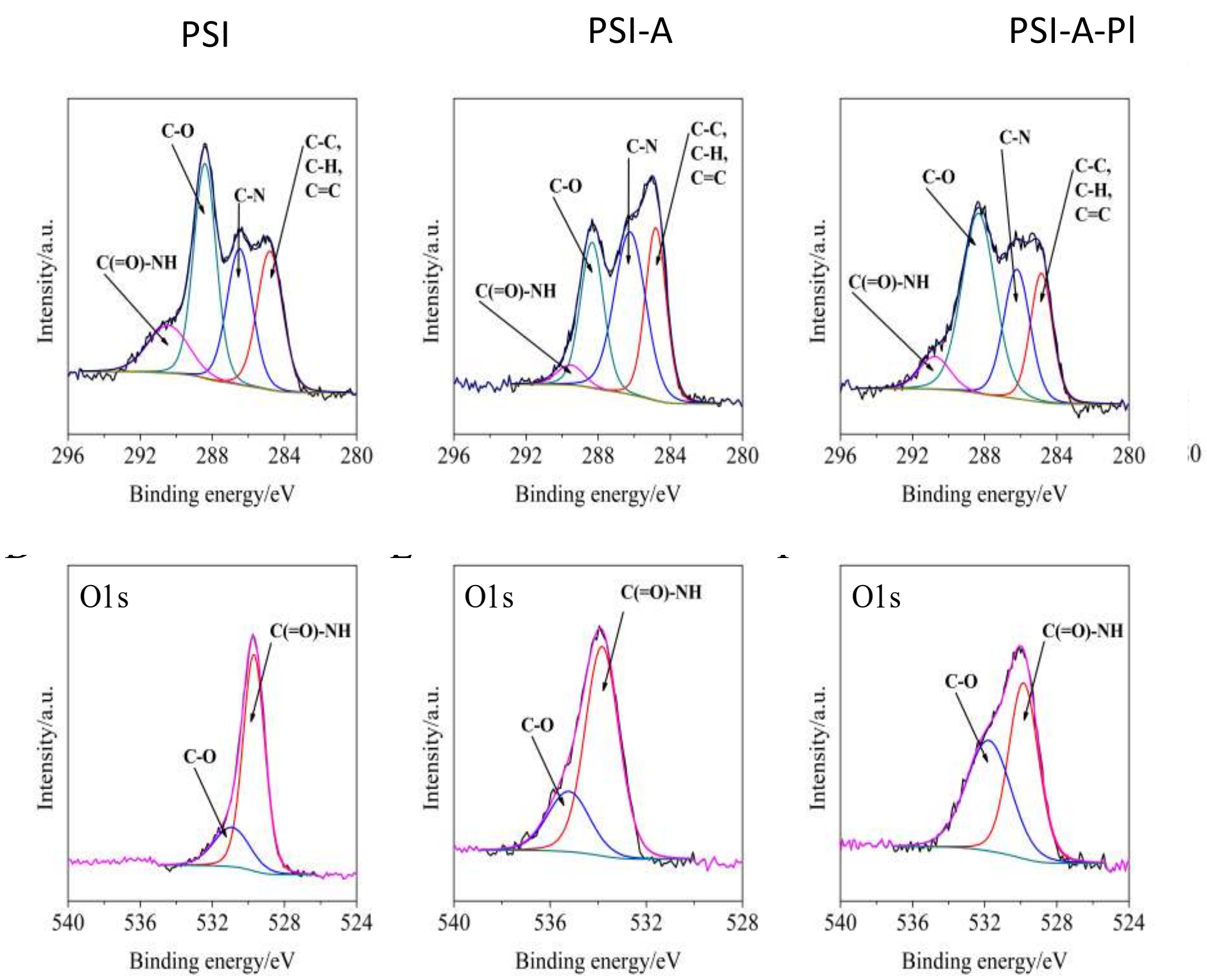


\section{Hydrolysis}

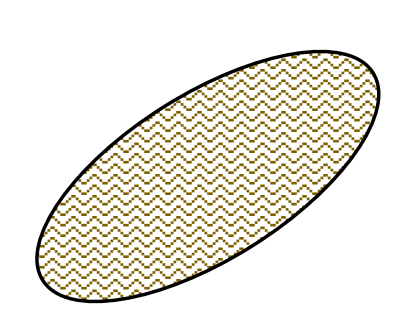

Plasma treated mat

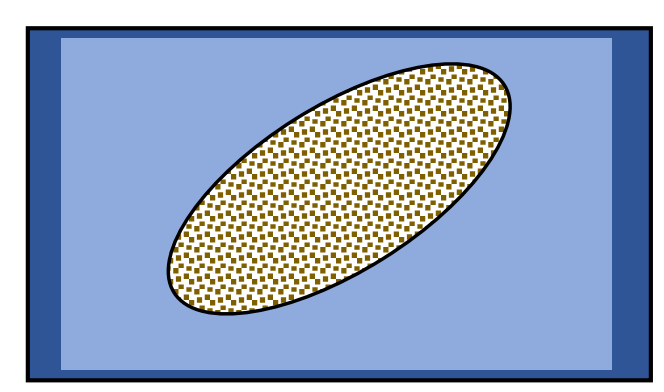

Hydrolysis, pH 7,4
Wash (MilliQ), Liofilization
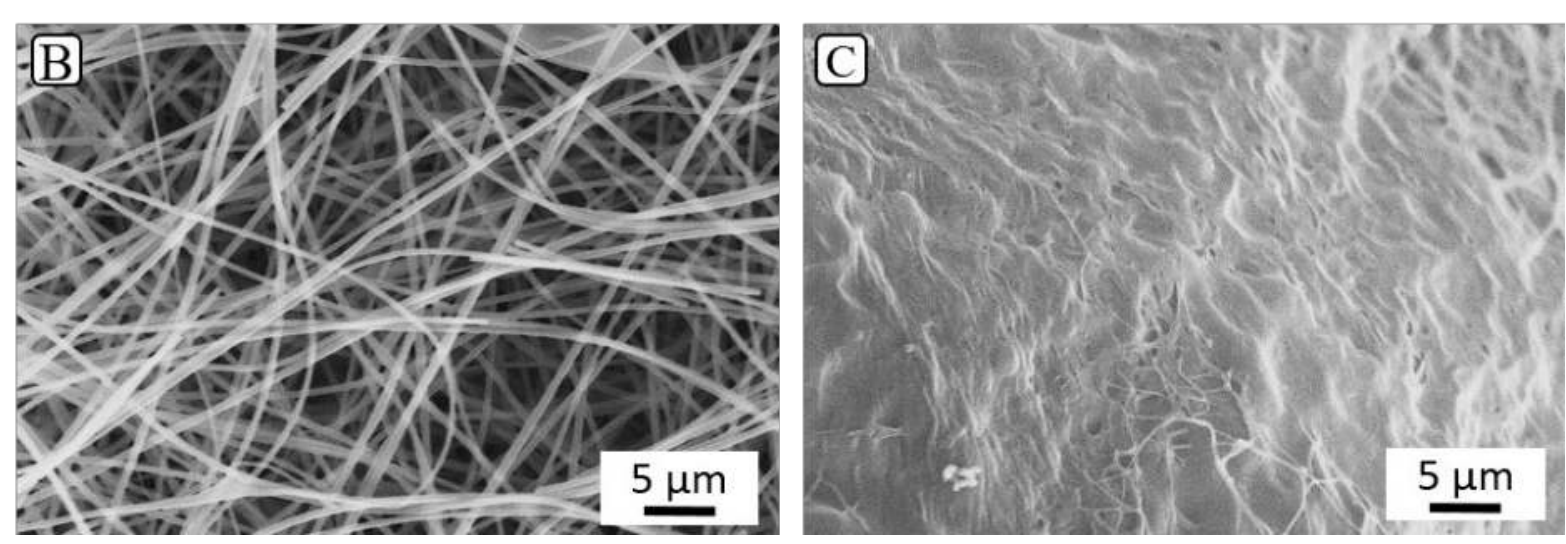


\section{Optimization of Plasma Treatment}

\section{Plasma 100W 17 minutes}

Hydrolysis
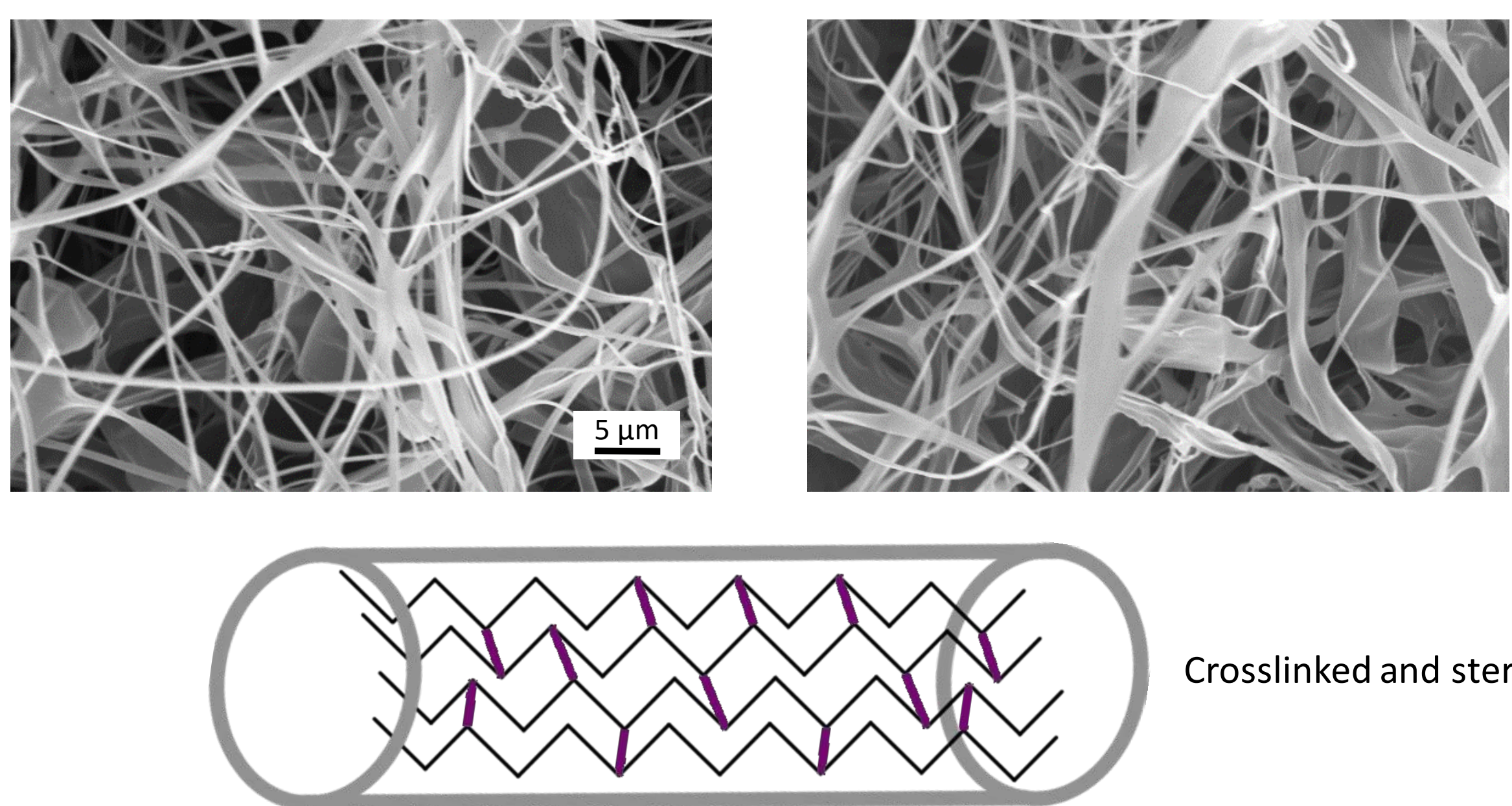

Crosslinked and sterilized mat 


\section{Sterility Test}
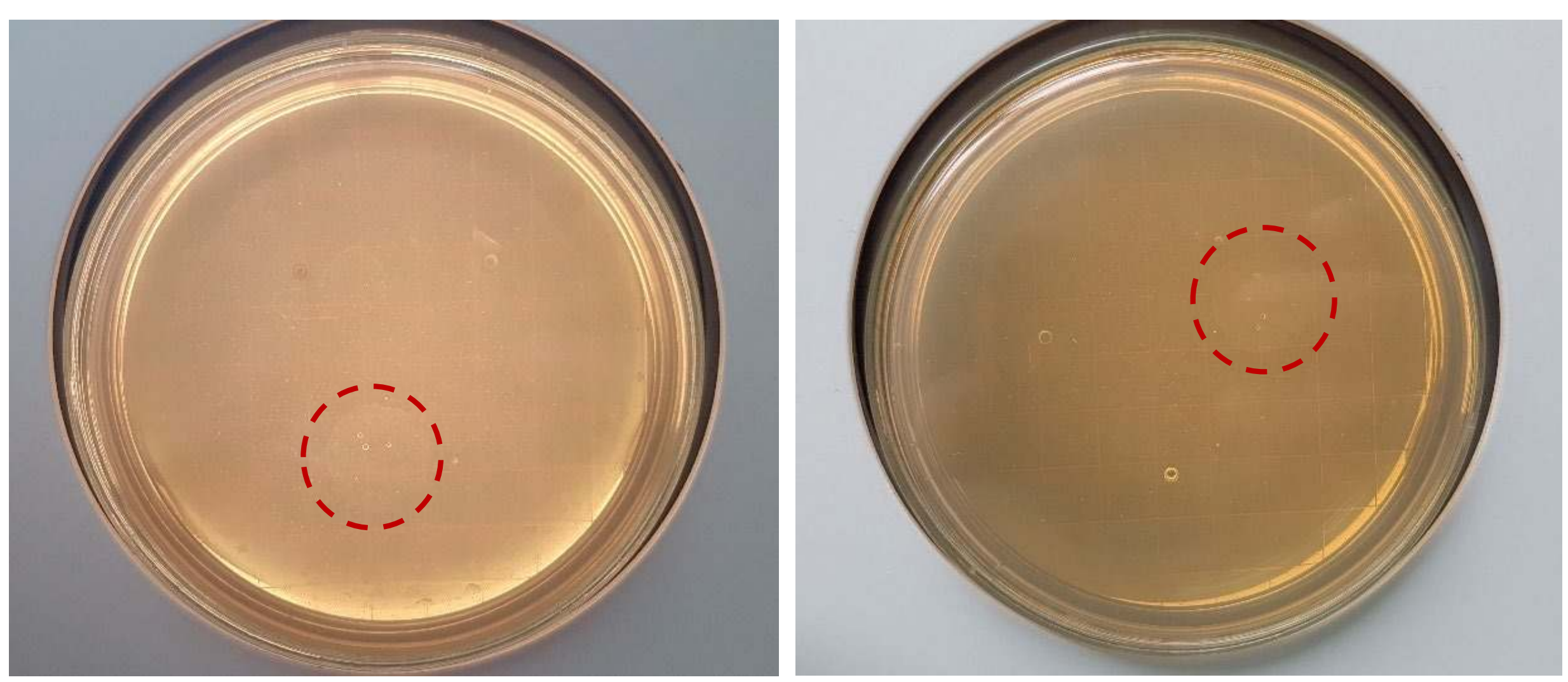

\section{4 hours}

Incubation at $37^{\circ} \mathrm{C}, \mathrm{CO}_{2}$ moisture

Soft agarose gel + buffer

48 hours

Hard agarose gel 


\section{Cytotoxicity}

MG63 osteosarcoma cell line 3700 cell/well

96 well plate

WST-1 reagents, $24 \mathrm{~h}, 72 \mathrm{~h}$

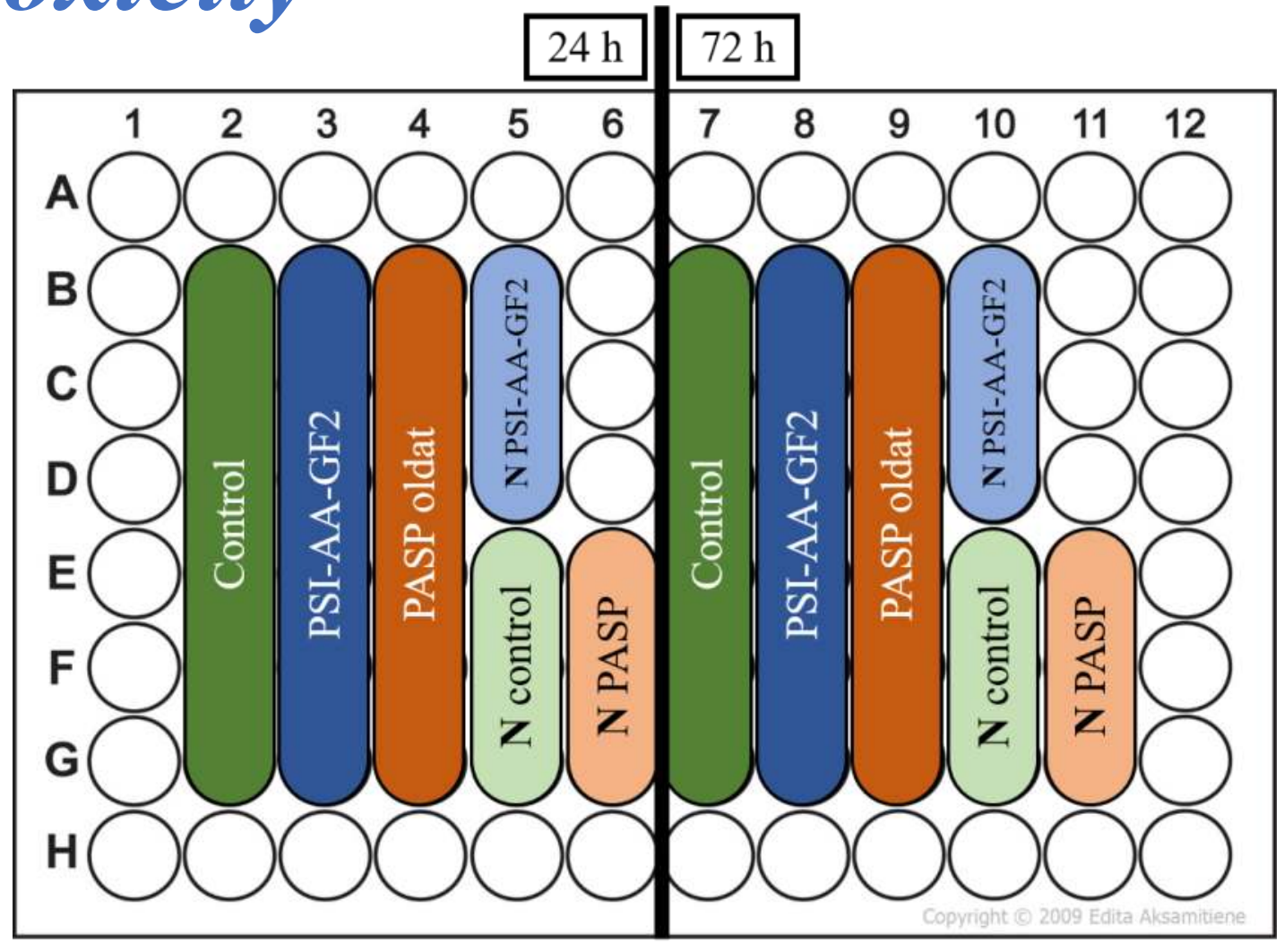

\section{Control}

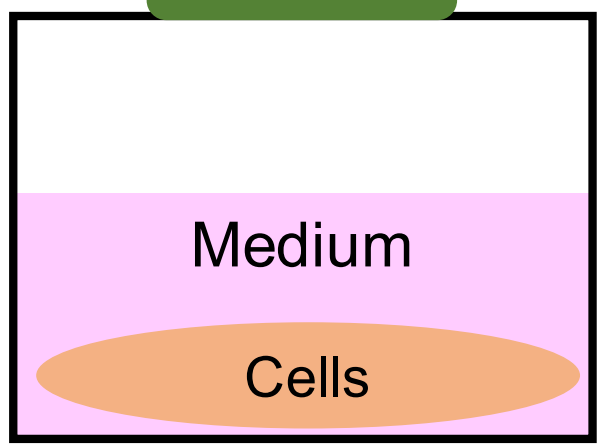

PSI-AA-GF2

PSI-AA mat

Medium

Cells
PASP solution

PASP extract

Medium 


\section{Cytotoxicity}

\section{Control}

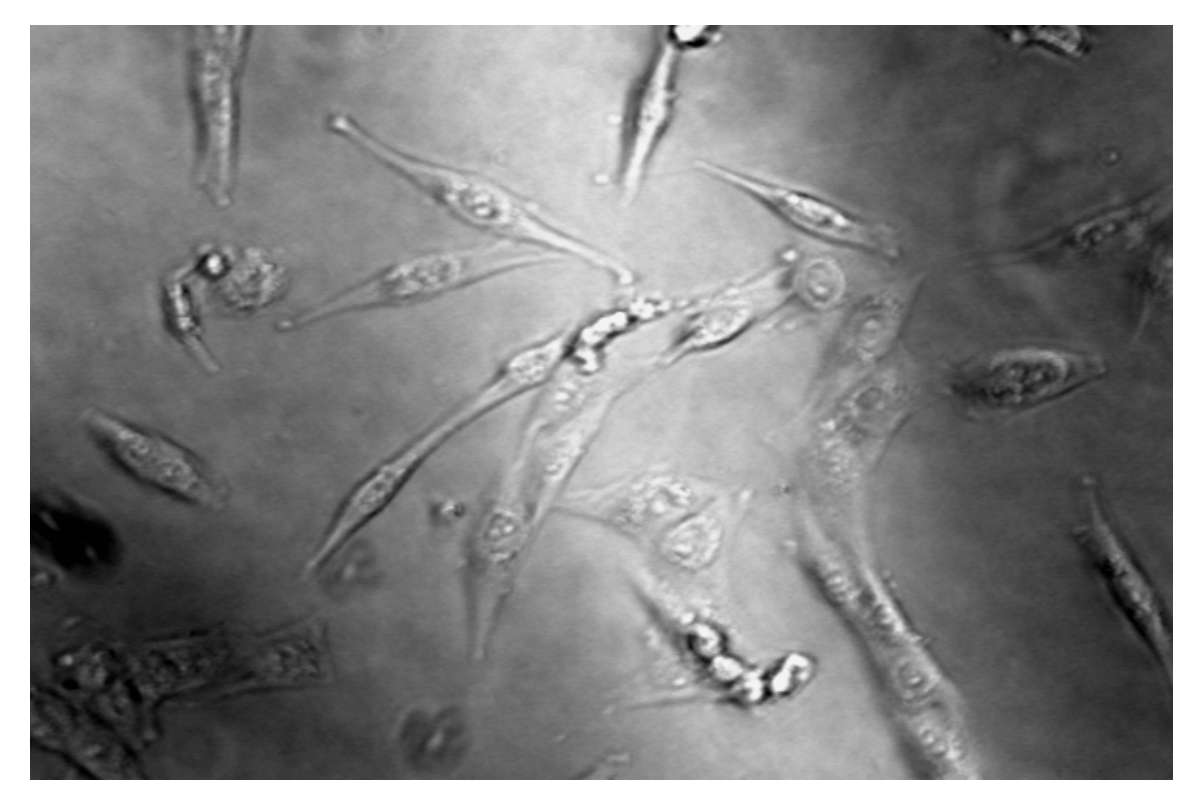

\section{PASP solution}

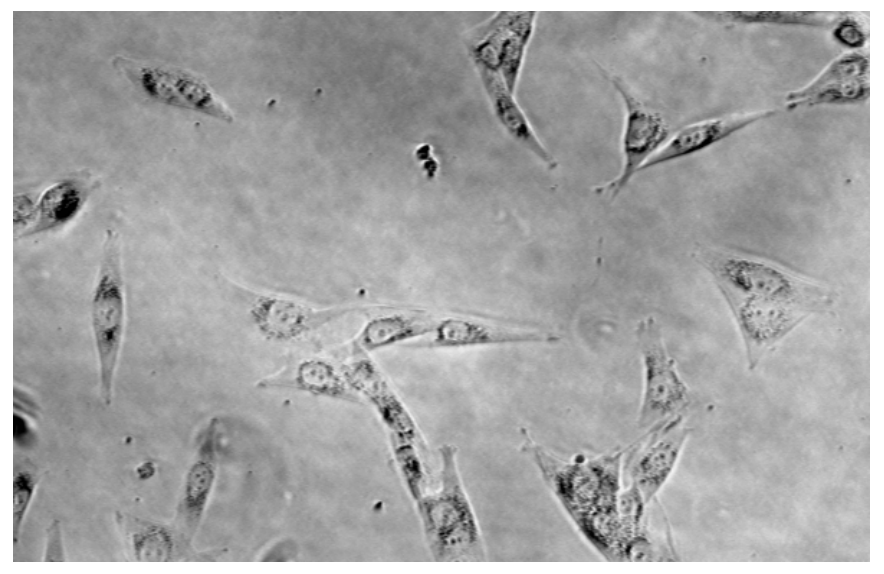

PSI-AA mat

24 hrs

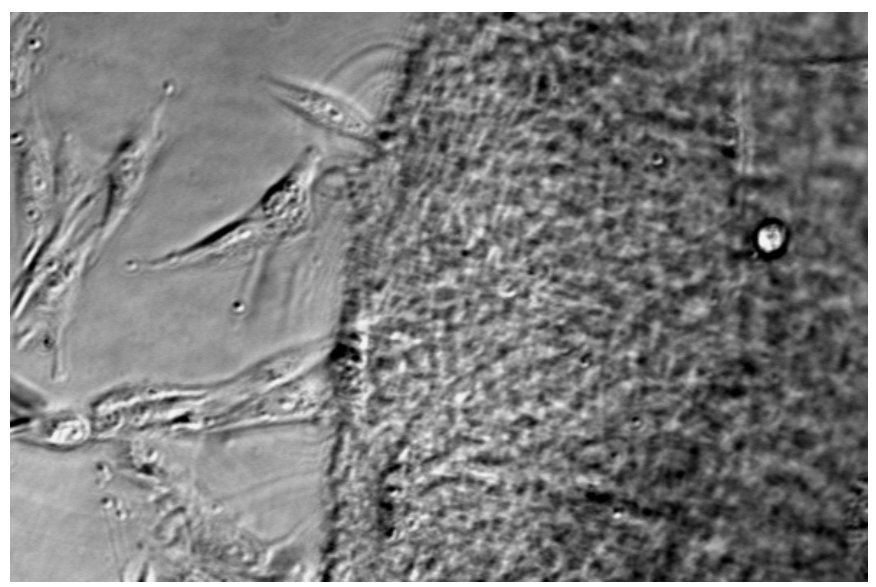




\section{Cytotoxicity}

Control

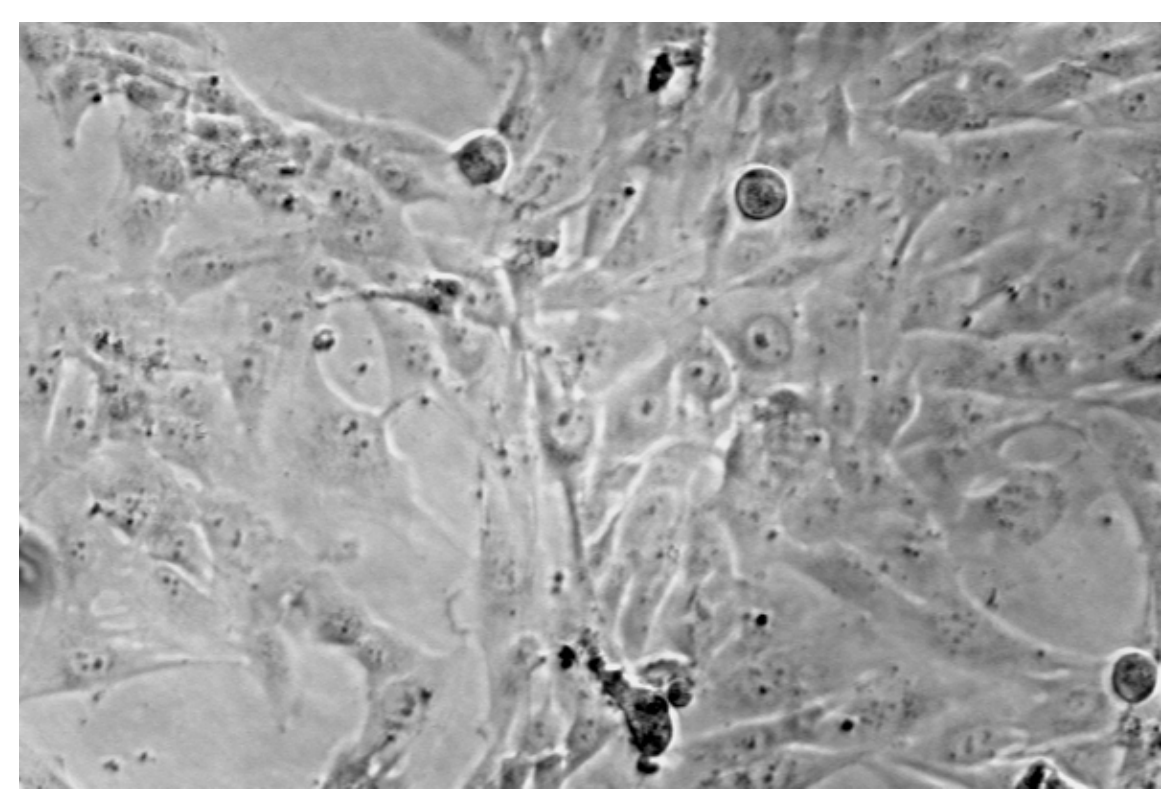

$72_{\text {hrs }}$

\section{PASP solution}

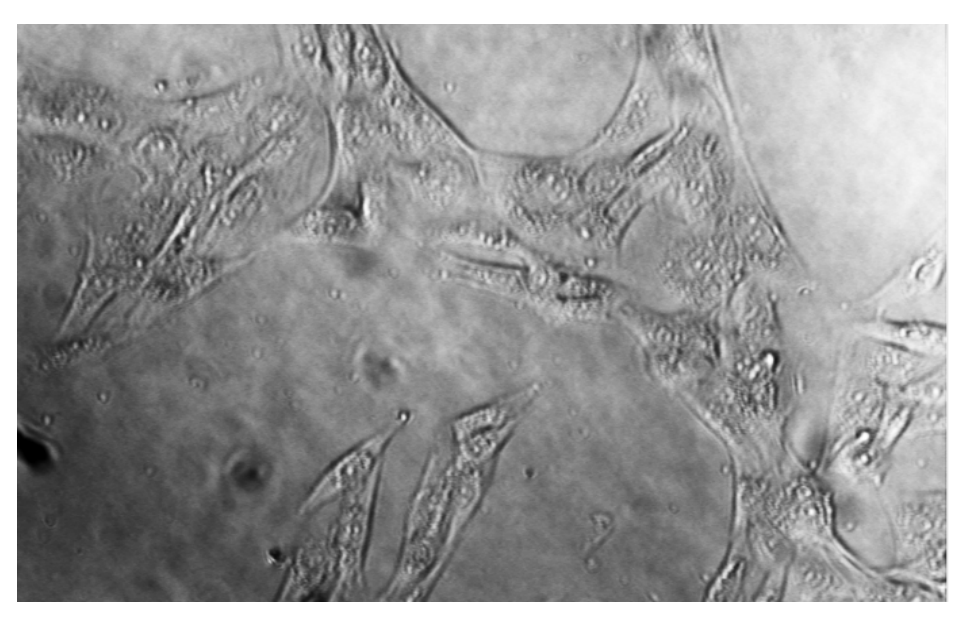

\section{PSI-AA mat}

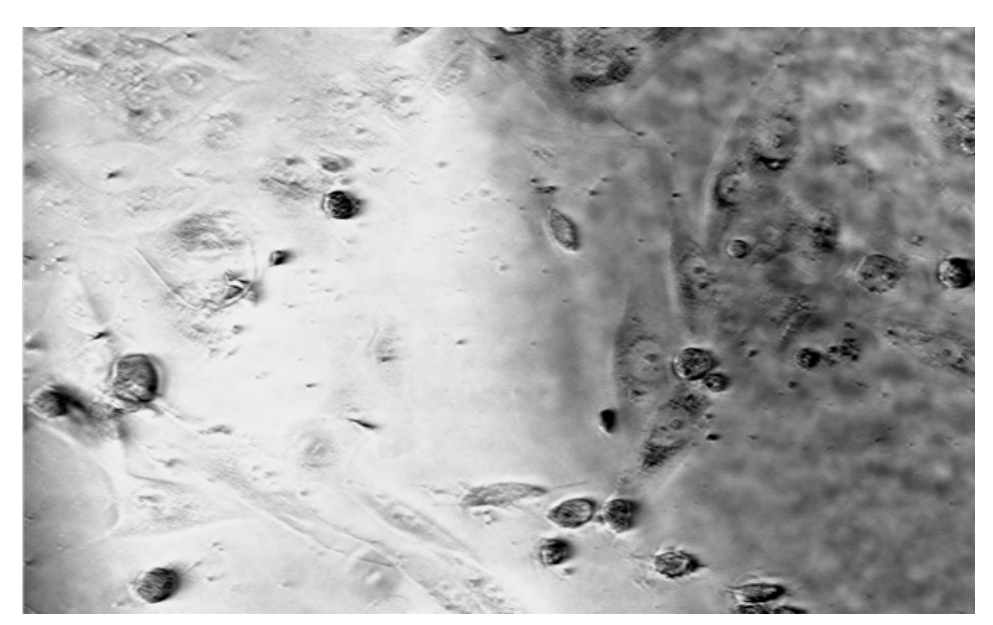




\section{Summary}

Polimer synthesis from renewable resources; Allyl grafting
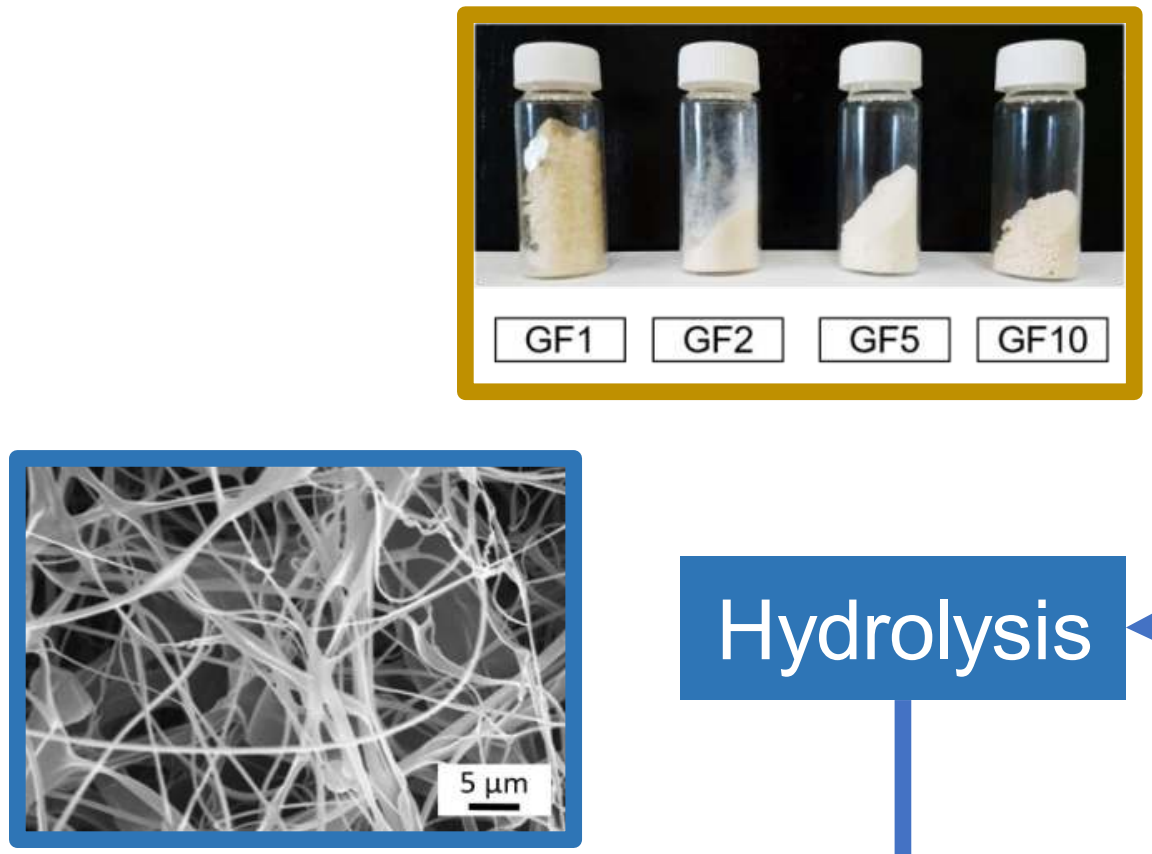

Steril, crosslinked mats with no cytotoxicity

Hydrolysis

\section{Electrospinning}

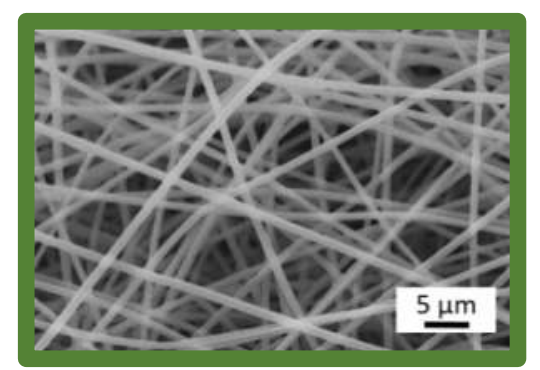

Plasma treatment
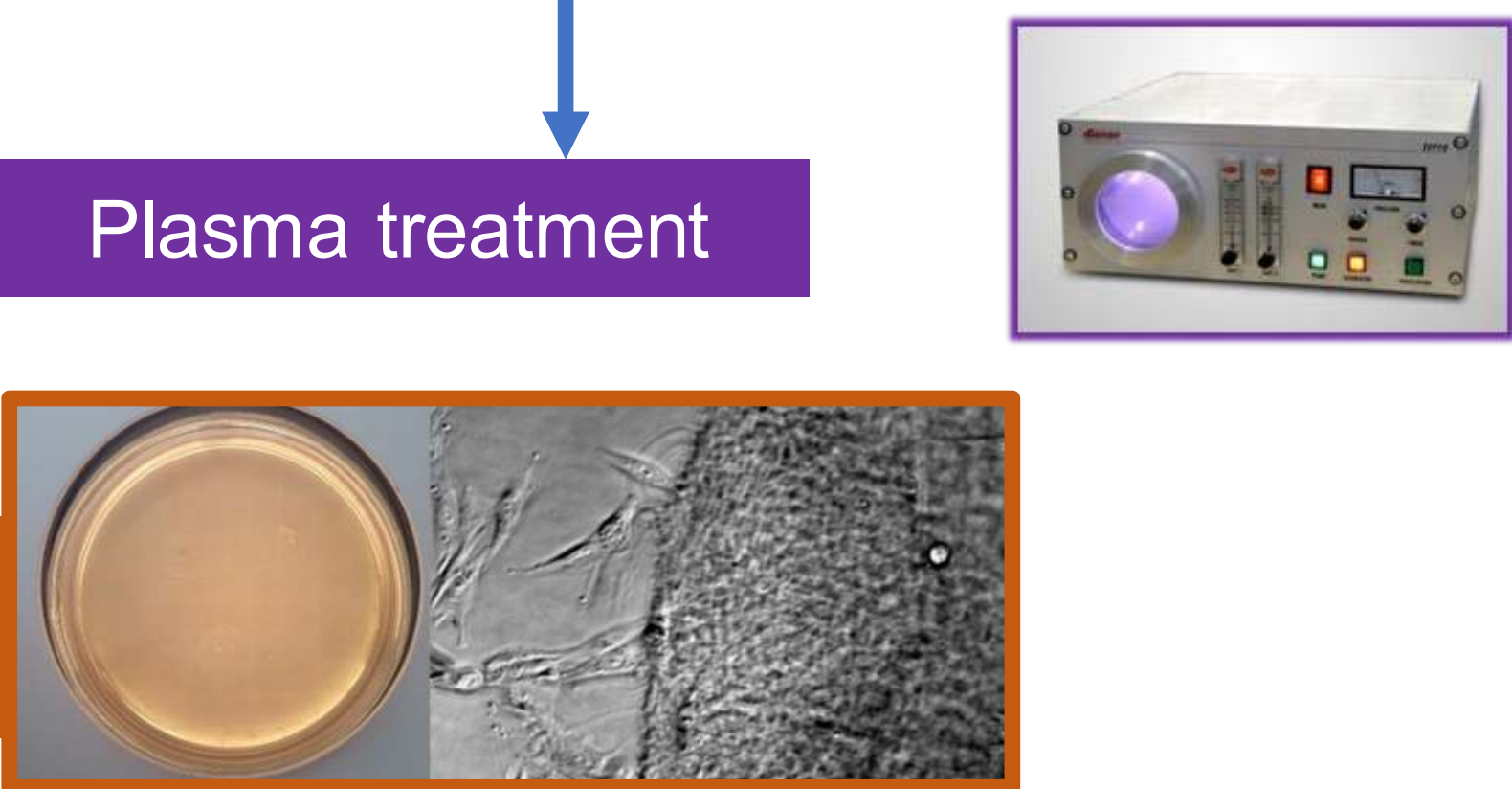


\section{Charles Goodyear Gold Medal}
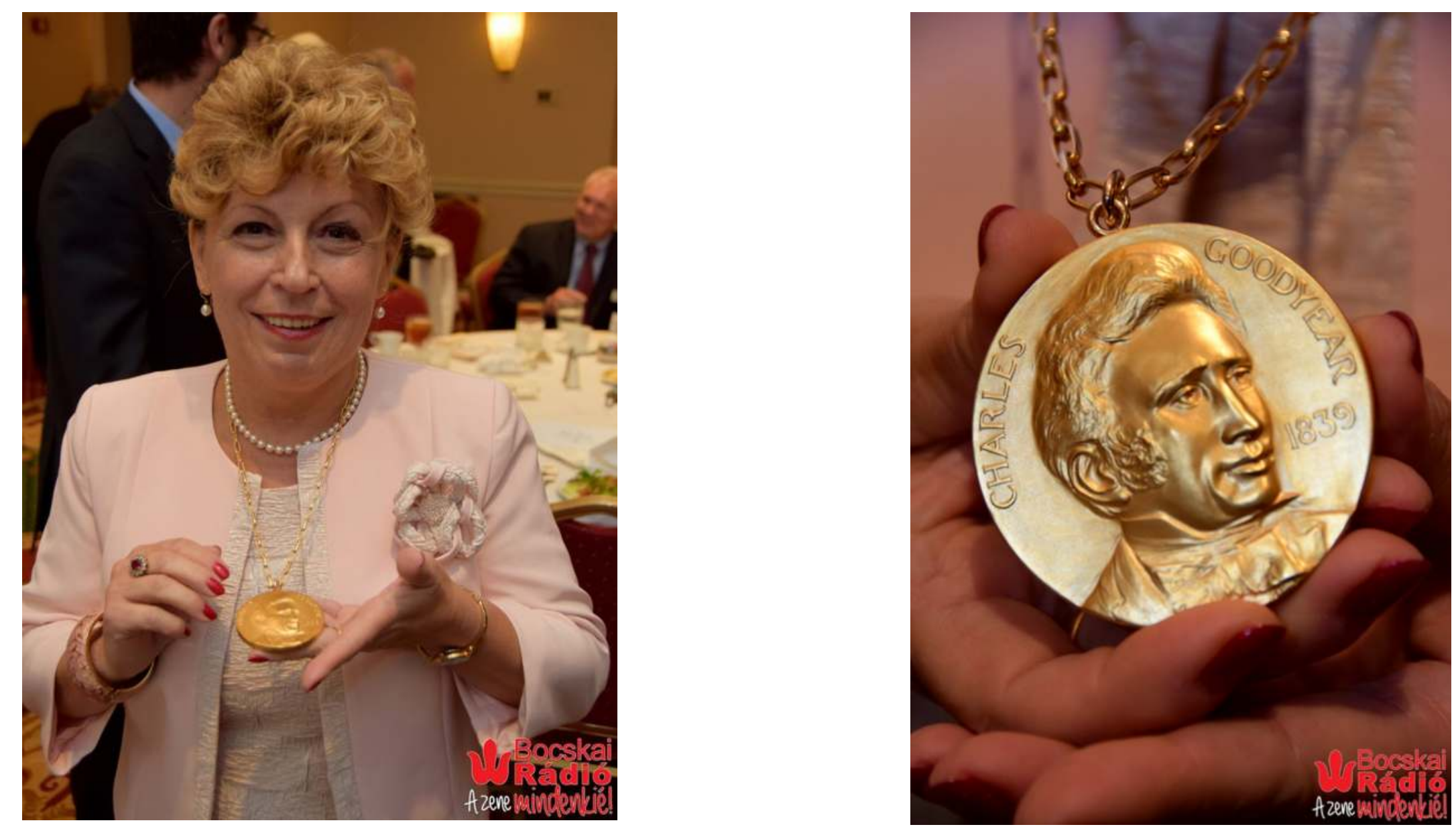


\section{Extended Current Puskas Group}
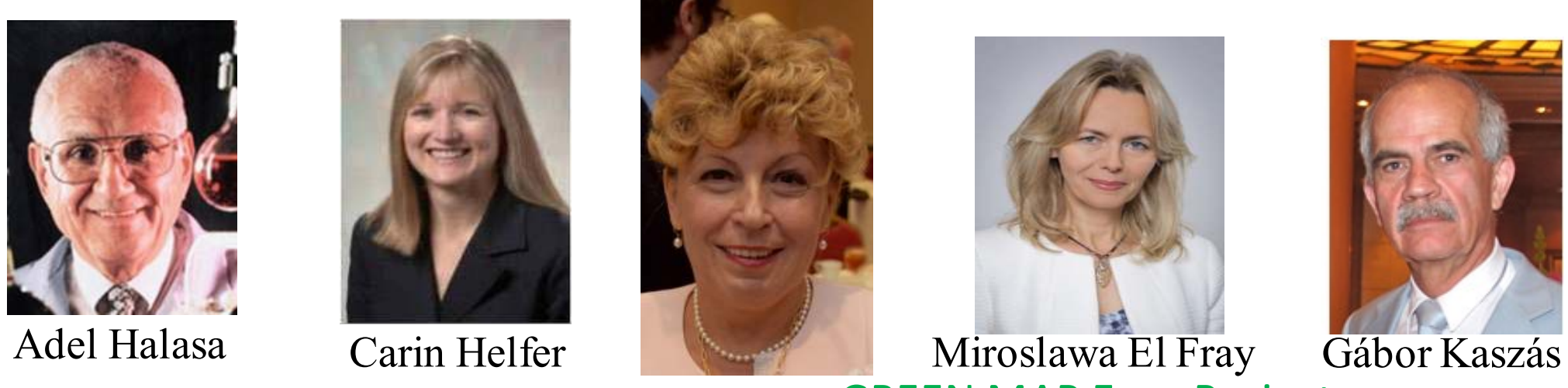

GREEN MAP Euro Project

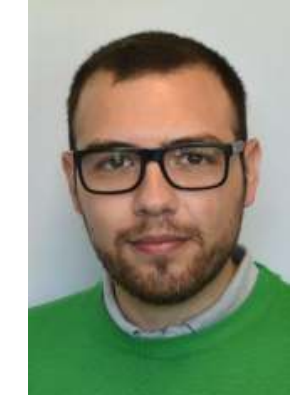

Mauricio Azevedo

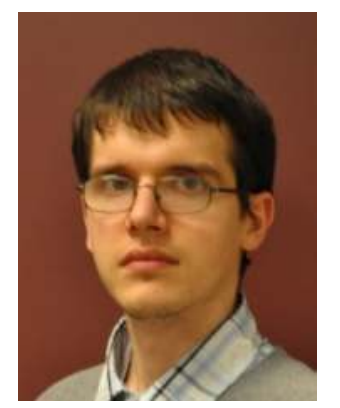

József Kántor

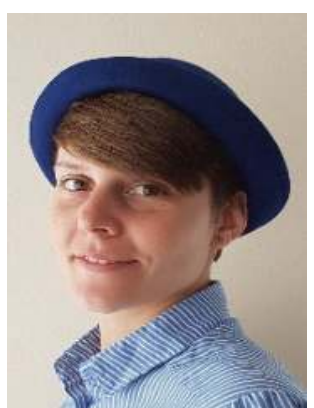

Enikő Krisch

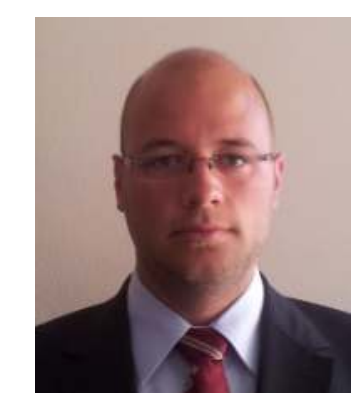

Kristóf Molnár

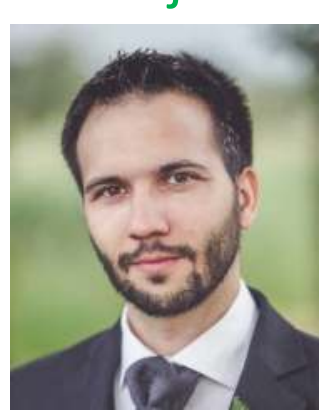

Kolos Molnár

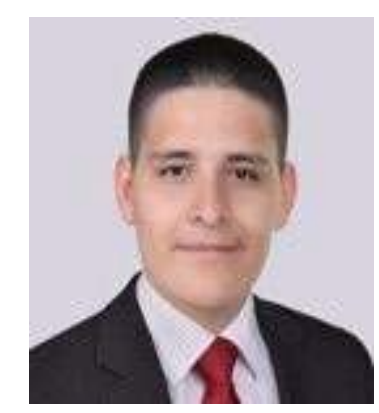

Andres Salgado

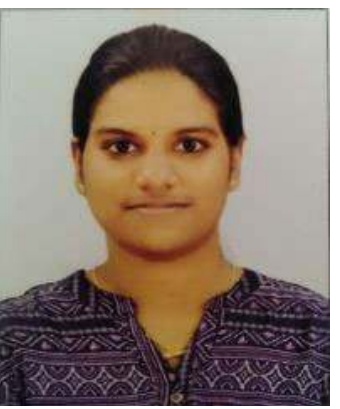

Geeta Aswati 


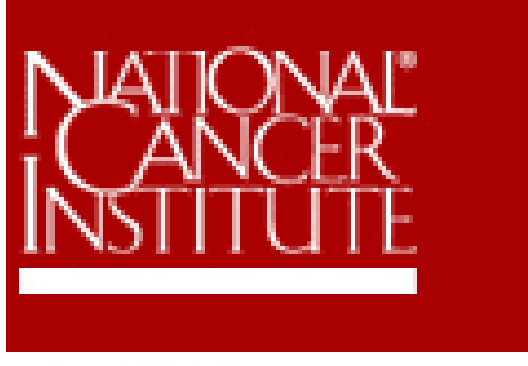

\section{Acknowledgements}

BREAST CANCER INNOVATION FOUNDATION
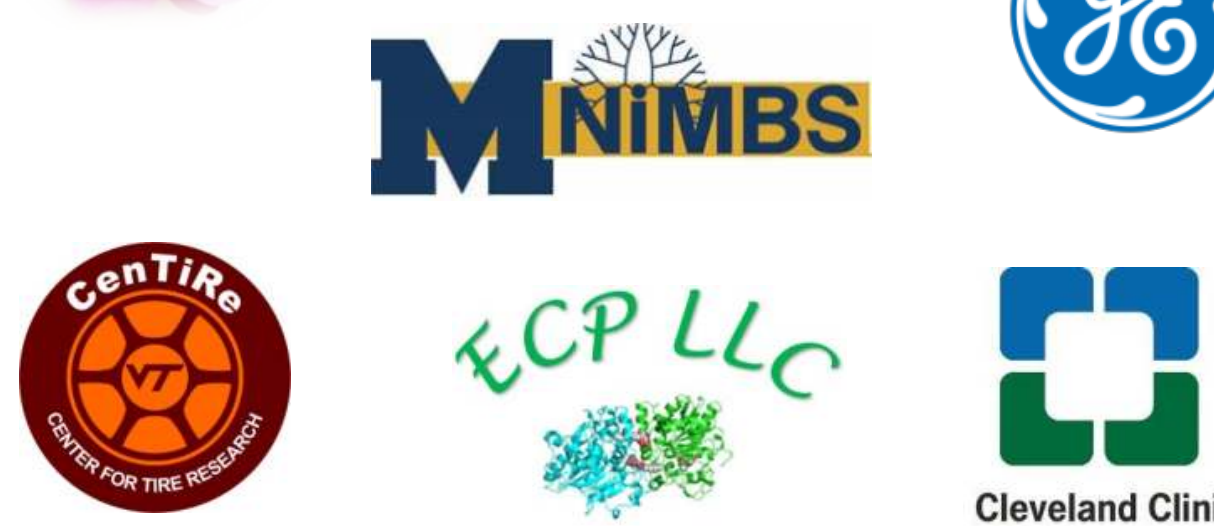

Cleveland Clinic
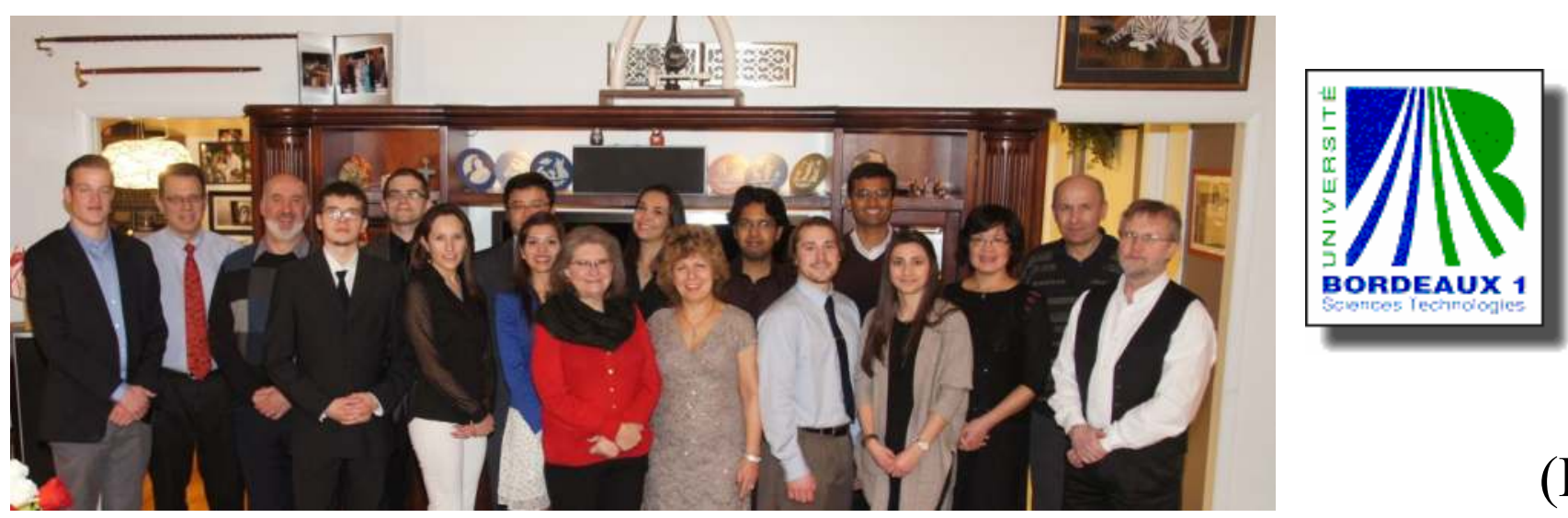

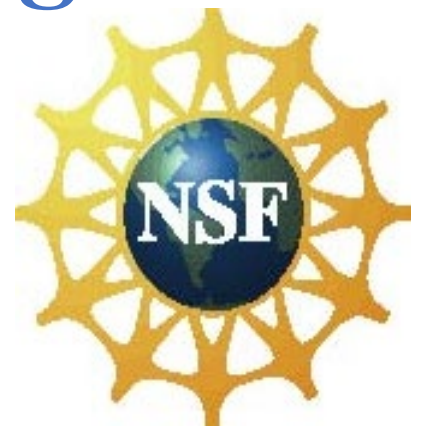

DMR \#0509687 \#0804878

Special Creativity Extension 2013 CHE \#0616834

$$
\text { \#1012636 }
$$

SBIR I, II: 2012, 2014

AIR 2014

NIH R15 AREA Austen CRD IUPAC DOE 2018 OSU 2019 ERC Planning 2019 GREEN MAP EURO 2019

PolyFiberMatrix LLC EnzymeCatalyzedPolymers LLC

\section{Rubber}

Division

International Center of Advanced Elastomers for Healthcare ICAEH

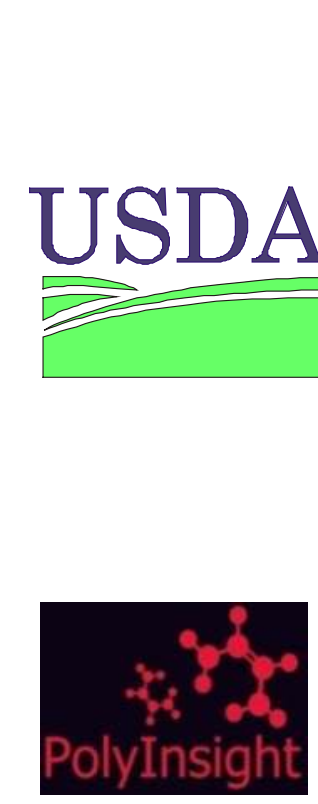

\section{CMPND}

OHPolymer.

SUMMA

Health System
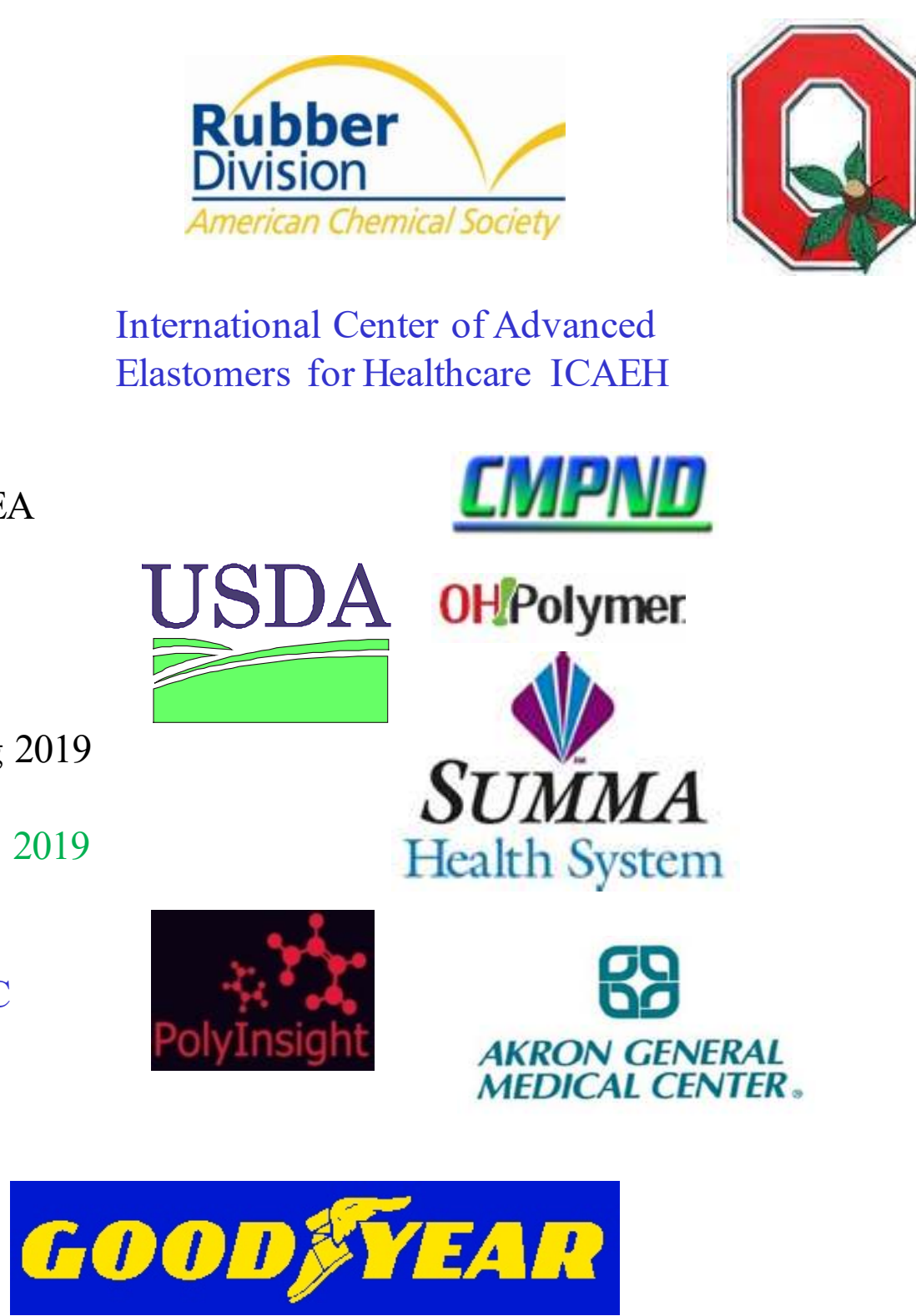

\section{LANXESS}

(Rubber Div., Bayer Inc.) 


\section{Acknowledgements}

The authors are grateful for the help of Surface Analysis Lab at The Ohio State University and NSF-DMR grant \#0114098 for the XPS measurements. This work was funded by the National Research, Development and Innovation Office - NKFIH FK 124147,

the János Bolyai Research Scholarship of the Hungarian Academy of Sciences (AJH) and by the ÚNKP-19-4-SE-04 new national excellence program of the Ministry for Innovation and Technology.

Financial support by the Start-up fund of The Ohio State University \#11232011000-11-PUSKAS and the Breast Cancer Innovation Foundation is also acknowledged.

The authors also acknowledge the exchange program of GREEN-MAP

(NOVEL GREEN POLYMERIC MATERIALS FOR MEDICAL PACKAGING AND DISPOSABLES TO IMPROVE HOSPITAL SUSTAINABILITY) H2020-MSCA-RISE-2019, European Commission, HORIZON 2020 Program 


\section{Puskas Group}

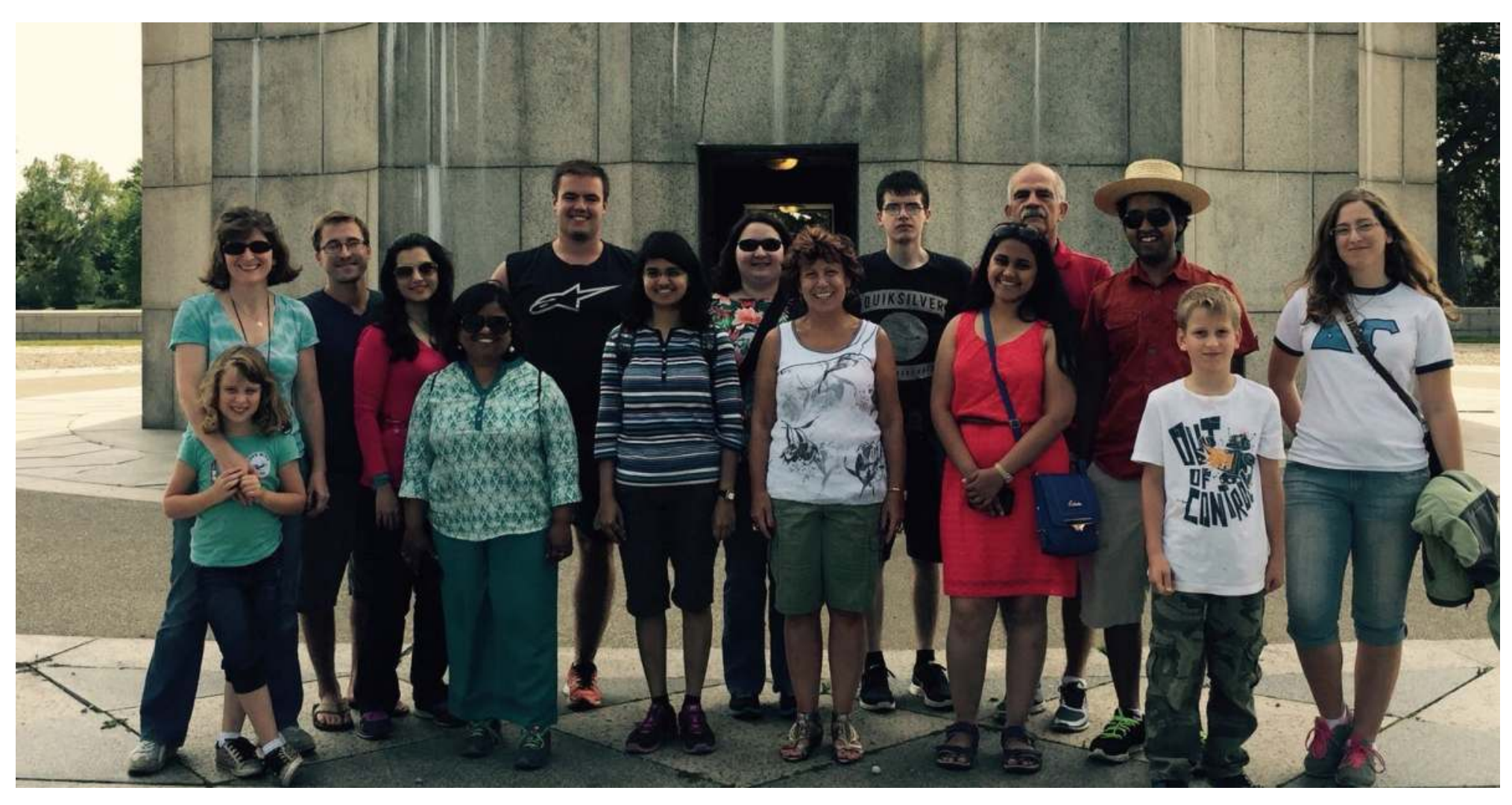




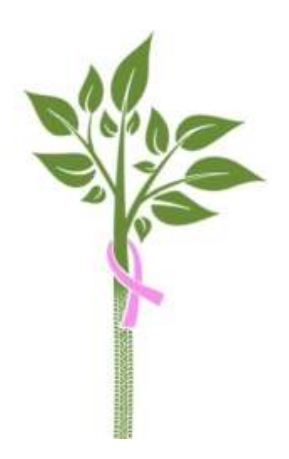

\section{Puskas Group}

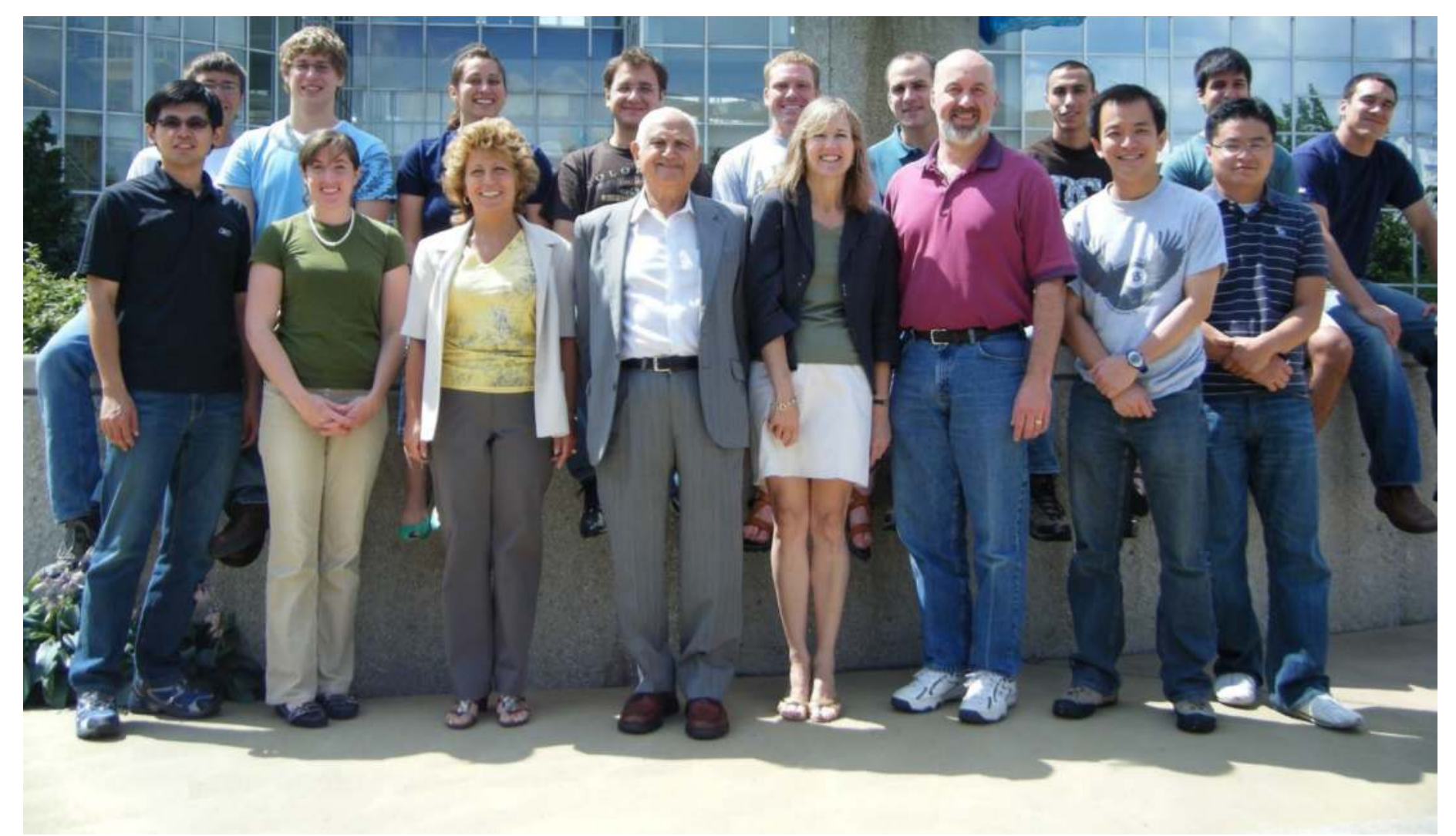




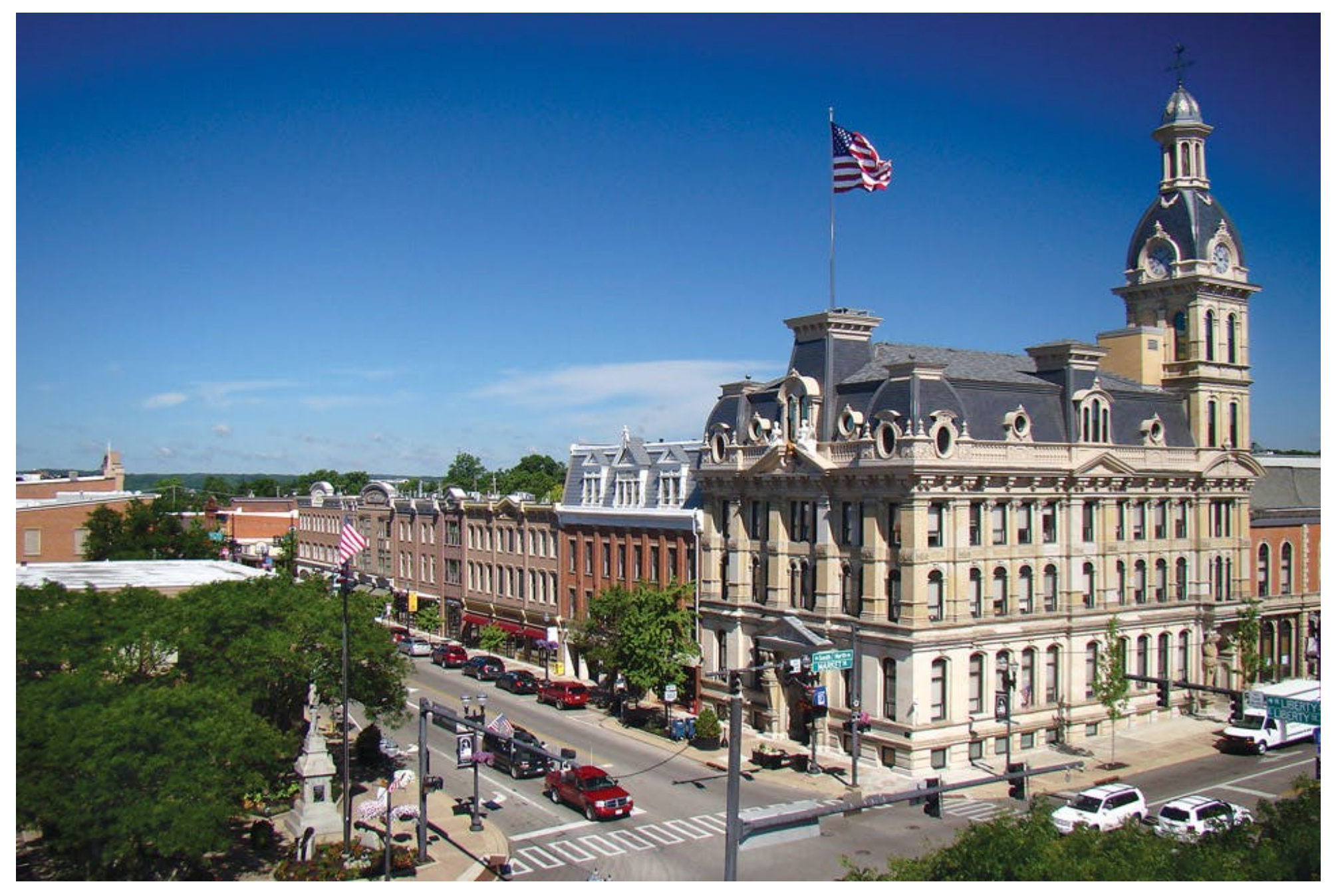

